\title{
Effects of Wind Stress and Surface Cooling on Cross-Shore Exchange
}

\author{
Xiaodong Wu, Douglas Cahl, And George Voulgaris \\ School of the Earth, Ocean and Environment, University of South Carolina, Columbia, South Carolina
}

(Manuscript received 12 October 2017, in final form 15 August 2018)

\begin{abstract}
The formation of coastal dense shelf water in winter provides the available potential energy (APE) to fuel baroclinic instability. The combined effects of baroclinic instability and wind forcing in driving cross-shelf exchange are investigated using idealized numerical simulations with varied bottom slope, wind stress, and heat loss rate. The results show that under upwelling-favorable winds, the intensity of the instability decreases as the wind stress increases. This is caused primarily by enhanced turbulence frictional dissipation. Under downwelling-favorable winds, an increase in wind stress and/or a decrease in heat loss rate tends to constrain the baroclinic instability, leading to a circulation resembling that driven purely by wind forcing. In the latter case, once a critical value of cross-shore density gradient is reached, isopycnal slumping is initiated, leading to increased vertical stratification and narrowing of the inner shelf. The change in depth of the inner-shelf outer boundary, defined as the location corresponding to the maximum cross-shore gradient of the surface Ekman transport, is proportional to an empirically derived multiparametric quantity $a_{2}^{-1 / 2} f^{-5 / 4} \sqrt{\alpha}\left|B / B_{0}\right|^{-\gamma / 2} \sqrt{|\tau| / \rho_{0}}$, where $a_{2}$ is a dimensional constant, $B_{0}$ is a constant heat loss rate, $\gamma=0.43, f$ is the Coriolis parameter, $\alpha$ is the shelf slope, $B$ is the heat loss rate, and $\tau$ is the wind stress. This relationship is found to hold for cases when instabilities are present.
\end{abstract}

\section{Introduction}

Subtidal alongshore flows are typically an order of magnitude larger than cross-shelf flows (Lentz and Fewings 2012) as a result of the polarization in the alongshore direction by the coastline. However, in terms of constituent exchanges (heat, salinity, nutrient, etc.), cross-shore fluxes are always more important than alongshore ones, mainly because of the higher cross-shore gradients of these constituents (Brink 2016a). This makes quantification of cross-shore exchanges a challenging but critical problem.

Wind-driven cross-shore circulation is characterized by the development of surface and bottom Ekman boundary layers that in the region of the mid-/outer shelf are separated by an intermediate layer (Austin and Lentz 2002; Lentz 2008). The schematics of winddriven shelf circulation found in Lentz and Fewings (2012, see Figs. 3 and 6 therein) provide an informative description of the processes involved in shelf dynamics. Under well-mixed conditions, Ekman transport can

Corresponding author: Xiaodong Wu, xwu@email.sc.edu be scaled by the product of shear velocity $u^{*}=\sqrt{\tau / \rho_{0}}$ and Ekman layer thickness $\delta_{\mathrm{Ek}}=\kappa u^{*} / f$, where $\tau$ is the alongshore wind stress, $\rho_{0}$ is a reference seawater density, $\kappa=0.41$ is the von Kármán constant, and $f$ is the Coriolis parameter (Madsen 1977). Within the inner shelf, the two boundary layers overlap, and crossshore flows gradually decrease to near zero at the coast. If the inner shelf is stratified, then wind-driven upwelling of bottom dense water onto the inner shelf tends to enhance stratification and suppress turbulence. It allows the development of current shear in the vertical and promotes cross-shore exchange within the inner shelf (Austin and Lentz 2002; Horwitz and Lentz 2014). In contrast, wind-driven downwelling contributes to vertical mixing and it constrains current vertical shear, limiting the cross-shore exchange within the inner shelf.

In addition to vertical stratification, a cross-shore density gradient can develop when dense water is formed inshore through surface cooling and/or an increase in salinity as a result of evaporation or ice formation (Ivanov et al. 2004; Shapiro et al. 2003). Typical examples include the polynyas in polar regions (Gill 1973), the Mediterranean salty outflow 
(Price et al. 1993), and the subtropical southwest Australian inner shelf undergoing winter cooling (Pattiaratchi et al. 2011). Along the East Coast of the United States, both the Middle and South Atlantic Bights (MAB and SAB, respectively) experience winter cooling (Brown and Beardsley 1978; Mathews and Pashuk 1984; Yoder and Ishimaru 1989). In an early study, Pringle (1998) revealed that surface cooling can drive the development of a crossshore density gradient on a sloping shelf. This is followed by the development of cross-shore flows, associated with geostrophic adjustment; it leads to cross-shore advection of density and contributes to vertical stratification on the shelf. In addition to the advection, numerical simulations (Gawarkiewicz and Chapman 1995; Jiang and Garwood 1996; Chapman and Gawarkiewicz 1997; Pringle 2001; Tanaka 2006) have shown that the dense water can also be transported offshore by eddies, which are associated with baroclinic instabilities.

Previous studies, such as those of Bretherton (1966), Hart (1979), and Pierrehumbert and Swanson (1995), have shown that the development of instabilities is related to the conversion of potential energy (PE) into eddy kinetic energy (EKE). According to Blumsack and Gierasch (1972), if the bottom slope is against that of the isopycnals, then baroclinic instability can occur, but the associated perturbations fall within a narrow band of possible wavenumbers. If the bottom inclines along the same direction as the isopycnals, then baroclinic instability can occur only if the shelf slope is smaller than that of the isopycnals. Once the slope angle exceeds that of the isopycnals, the water column becomes stable. In the presence of the Ekman boundary layer, baroclinic instability is constrained, as bottom Ekman transport can contribute to the release of available potential energy (APE) and bottom friction damps the kinetic energy (Lin and Pierrehumbert 1988).

Studies by Mahadevan et al. (2010) and Brink (2017, hereinafter B17) have shown that the intensity of baroclinic instability is also affected by wind forcing. Numerical simulations of wind-driven upwellingdownwelling circulation (Brink 2016b) have shown that the resulting horizontal density gradient can provide the APE required for the development of baroclinic instability. Baroclinic instability increases with increasing values of bottom slope, initial stratification, and/or the duration of steady wind forcing. The bottom slope enhances instabilities by providing more APE (i.e., larger cross-shore density gradient) and this overcomes the stabilizing effect of the bottom slope on the water column (Blumsack and Gierasch 1972).
Brink and Seo (2016) have shown that instabilities can develop even under fluctuating winds, regardless of wind direction, and that lower-frequency fluctuations enhance instabilities. B17 used numerical simulations to examine the combined effects of surface cooling and wind forcing. He showed that under no wind forcing, the instability-driven eddy heat flux is larger than that associated with mean cross-shore flow. Under downwelling-favorable winds, as wind stress increases, the mean heat flux strengthens, while the eddy heat flux weakens. Under upwelling-favorable winds, eddies transport heat onshore and this onshore flux is partially compensated by an offshore-directed mean heat flux. In this case, as wind stress increases, instabilities strengthen and the mean heat flux becomes less important.

Although the coupled effects of baroclinic instabilities and wind forcing on cross-shore exchange have been examined in detail in B17 and references therein, there are still issues that merit further investigation. B17 showed that under downwellingfavorable winds, wind-driven cross-shore flows release APE and instabilities can be inhibited. In this case, and if surface cooling persists, does the crossshore density gradient keep increasing? What is the role of wind-driven currents in controlling this gradient? Furthermore, B17 showed that upwellingfavorable winds tend to enhance instabilities through the supply of additional APE. Under such conditions, can the wind-forced mixing inhibit instabilities, especially for relatively strong wind forcing on a shallow shelf? These questions are addressed in this manuscript using idealized numerical simulations. In section 2, the numerical model, its configuration, and the corresponding runs are described. Section 3 presents the model results for downwelling- and upwelling-favorable wind conditions. The interactions between wind-driven circulation and baroclinic instability are discussed in section 4. Finally, conclusions are presented in section 5 .

\section{Methodology}

The numerical simulations were carried out using the Regional Ocean Modeling System (ROMS), a threedimensional, free-surface, terrain-following, primitiveequation ocean model with hydrostatic and Boussinesq approximations (Shchepetkin and McWilliams 2005). ROMS splits the equations into fast (barotropic) and slow (baroclinic) components that can be implemented using different time steps ( 3 and $30 \mathrm{~s}$, respectively, in this study). 
The model domain is a symmetrical channel with sloping sides that represent an alongshore $(y)$ uniform continental

$$
h(x)=\left\{\begin{array}{l}
h_{0}+\alpha x \\
h_{0}+\alpha W_{1}+\beta\left(x-W_{1}\right) \\
h_{0}+\alpha W_{1}+\beta W_{2} \\
h_{0}+\alpha W_{1}+\beta\left(W_{1}+2 W_{2}+W_{3}-x\right) \\
h_{0}+\alpha\left(2 W_{1}+2 W_{2}+W_{3}-x\right)
\end{array}\right.
$$

where $h_{0}(=2 \mathrm{~m})$ is the water depth at the coastal boundary; $\alpha$ and $\beta$ are the slopes of the continental shelf and slope, respectively; $W_{1}(=80 \mathrm{~km})$ and $W_{2}(=10 \mathrm{~km})$ are the corresponding widths of the shelf and slope; $W_{3}$ $(=40 \mathrm{~km})$ is the width of the bottom channel that separates the two sides.

Three values of shelf slope $\alpha$ (i.e., $0.5 \times 10^{-3}$, $0.75 \times 10^{-3}$, and $1.0 \times 10^{-3}$; see Table 1$)$ are assigned. These are much smaller than the slope $(2.1 \times$ $10^{-3}$ ) used in B17, but they are representative of the relatively wide and shallow shelf in the SAB. The slope of the continental slope is kept constant at $2.0 \times 10^{-2}$. The alongshore channel length $L$ is set to $60 \mathrm{~km}$, much larger than the horizontal eddy scales on continental shelves, which are reported to be on the order of $5-10 \mathrm{~km}$ (Brink 2016b). By increasing $L$ to $90 \mathrm{~km}$, EKE changes by $5 \%$, while APE remains the same. Similarly, runs with an increased $\mathrm{W} 3$ value to $80 \mathrm{~km}$ resulted in a $10 \%$ change in EKE and no change for APE. The grid spacing in the alongshore is kept constant at $250 \mathrm{~m}$; in the cross-shore, it decreases linearly from $250 \mathrm{~m}$ at the center of the channel to $150 \mathrm{~m}$ at the coastal boundary. The horizontal domain consists of $1060 \times 240$ cells in the cross-shore and alongshore directions, while $30 \sigma$ levels are used in the vertical with enhanced resolution near the surface and bottom.

A periodic boundary condition is imposed on the two open sides of the domain. The surface forcing consists of a spatially uniform, constant alongshore wind stress $\tau$ and constant surface heat loss rate $B(<0$, surface cooling). Four levels of wind stress are used, representing no wind, average ( 0.02 and $0.04 \mathrm{~Pa})$, and relatively strong $(0.08 \mathrm{~Pa})$ wind conditions. The wind stress ramps up to its prescribed value within 1 day and then remains constant. Atkinson et al. (1983) showed that in winter (OctoberFebruary), the mean heat exchange rate in the SAB is approximately $-50 \mathrm{~W} \mathrm{~m}^{-2}$ and the monthly mean during this season ranges from -20 to $-100 \mathrm{~W} \mathrm{~m}^{-2}$. Based on these results, three representative heat loss rates $\left(-20,-50\right.$, and $\left.-100 \mathrm{~W} \mathrm{~m}^{-2}\right)$ are used in this work. This surface heat flux is imposed at the start of each shelf and a continental slope on each side (Fig. 1). The crossshore bathymetry $h(x)$ is constructed analytically using

$$
\begin{aligned}
x & \leq W_{1} \\
W_{1} & <x \leq\left(W_{1}+W_{2}\right) \\
\left(W_{1}+W_{2}\right)<x & \leq\left(W_{1}+W_{2}+W_{3}\right) \\
\left(W_{1}+W_{2}+W_{3}\right) & <x \leq\left(W_{1}+2 W_{2}+W_{3}\right) \\
\left(W_{1}+2 W_{2}+W_{3}\right)<x & \leq\left(2 W_{1}+2 W_{2}+W_{3}\right)
\end{aligned}
$$

simulation and it is held constant for the entire duration. The seawater is initially homogenous with a temperature of $14^{\circ} \mathrm{C}$. Water density is calculated with the linear equation of state. The surface heat flux can be converted into a temperature flux across the surface using the specific heat capacity $c_{p}$ for seawater $\left(3985 \mathrm{~J} \mathrm{~kg}^{-1}{ }^{\circ} \mathrm{C}^{-1}\right)$.

Eddy viscosity and diffusivity are estimated using the Mellor-Yamada 2.5 turbulence closure scheme (Mellor and Yamada 1982). The background values are $10^{-5}$ and $10^{-6} \mathrm{~m}^{2} \mathrm{~s}^{-1}$ for the vertical eddy viscosity and vertical diffusivity, respectively. A constant Coriolis parameter $f\left(=7.94 \times 10^{-5} \mathrm{~s}^{-1}\right)$ is assigned that corresponds to the subtropical latitude of $33^{\circ} \mathrm{N}$ (roughly the middle of the $\mathrm{SAB}$ ). The bottom stress is determined using a logarithmic bottom drag scheme with a bottom roughness of $z_{0}=1 \mathrm{~cm}$, as in Horwitz and Lentz (2014). This relatively high value of bottom roughness is selected to simulate the effect of tide-induced mixing that is not incorporated here. Various combinations of the three parameters $(\tau, B, \alpha)$ were used, leading to a total of 36 model setups (see Table 1 ). Additional simulations were carried out using $z_{0}=0.01 \mathrm{~cm}$. These runs were limited to four wind conditions $(0,0.02,0.04$, and $0.08 \mathrm{~Pa})$ with $\left(B=-100 \mathrm{~W} \mathrm{~m}^{-2}, \alpha=1.0 \times 10^{-3}\right)$ and the purpose was to examine the effects of bottom friction on instabilities. Each simulation was carried out with and without any instabilities present. The instability is triggered by adding a small perturbation in the wind stress over the first 5 days of the simulation. The imposed perturbation has a zero mean and a standard deviation of $10^{-4} \mathrm{~Pa}$. All model runs were carried out for a period of 150 days and forced by constant nonzero surface cooling rate. Although this cooling period matches the climatologically defined winter cooling period in the SAB (from October to February), the constant cooling rate does not realistically represent the temporal variation in cooling. This long period ensures that EKE reaches a plateau, similar to that showed in B17, from which the individual effects of bottom slope, wind stress, and heat loss rate can be identified. Results from the two sides (shelves) of the model domain are 


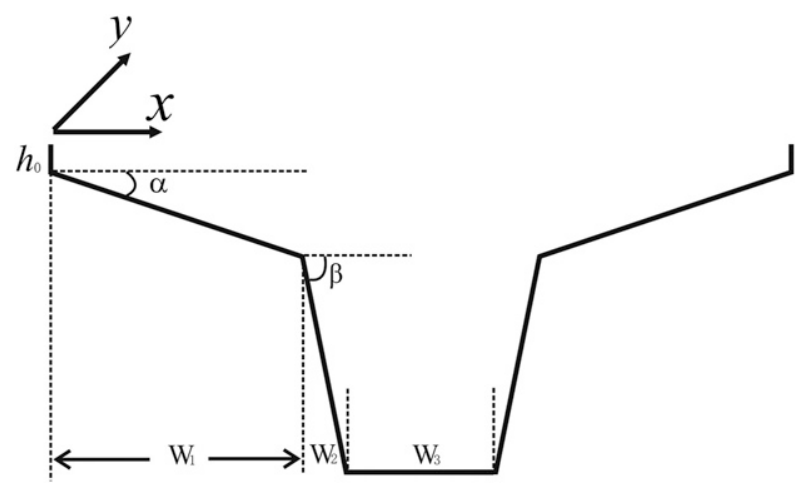

FIG. 1. Schematic of cross-shore channel profile.

presented separately as two individual runs that represent the dynamics of a Northern Hemisphere "East Coast" but with opposite wind directions (i.e., upwelling and downwelling). In all cases, the crossshore coordinate is converted so that $x=0$ at the coast and it increases offshore. Positive alongshore $y$ direction is aligned with the direction of upwellingfavorable winds.

Consistent with B17, we use several diagnostic quantities that are based on calculations of an alongshore average of the quantity of interest $\langle q(x, z, t)\rangle$ and its deviation from its mean $q^{\prime}(x, z, t)$, where $z$ is the vertical coordinate and $t$ is time. The spatially averaged (over depth and cross-shore distance) EKE is given by

$$
\operatorname{EKE}(t)=\frac{1}{2 A} \int_{-h}^{0} \int_{0}^{W}\left\langle u^{2}+v^{2}\right\rangle d x d z
$$

where $u$ and $v$ are the horizontal velocity components, $W$ is the cross-shore distance extending to the middle of the domain, and $A$ is the cross-shore area of the domain. Prior to calculating APE at each time step, the spatially averaged potential energy was calculated using

$$
\operatorname{PE}(t)=\frac{1}{A} \int_{-h}^{0} \int_{0}^{W}\langle\rho\rangle g z d x d z
$$

where $\rho$ is the seawater density and $g$ is gravitational acceleration. Subsequently, the density field was arranged so that the isopycnals are flat and the water column is stably stratified. The potential energy is then recalculated using Eq. (2.3) and the difference between the two estimates defines the APE. This approach is similar to the method described in Winters et al. (1995).

In addition to the aforementioned parameters, the conversion rates from $\mathrm{PE}$ to EKE and from mean kinetic energy (MKE) to EKE (denoted as $C_{\mathrm{sp}}$ and $C_{\mathrm{sk}}$, respectively) were estimated using

$$
\begin{aligned}
C_{\mathrm{sp}}= & -\frac{g}{\rho_{0} A} \int_{-h}^{0} \int_{0}^{W}\left\langle\rho^{\prime} w^{\prime}\right\rangle d x d z, \\
C_{\mathrm{sk}}= & \frac{1}{A} \int_{-h}^{0} \int_{0}^{W}\left\langle-\left\langle u^{\prime} v^{\prime}\right\rangle \frac{\partial\langle\boldsymbol{v}\rangle}{\partial x}-\left\langle u^{\prime} u^{\prime}\right\rangle \frac{\partial\langle u\rangle}{\partial x}\right. \\
& \left.-\left\langle v^{\prime} w^{\prime}\right\rangle \frac{\partial\langle\boldsymbol{v}\rangle}{\partial z}-\left\langle u^{\prime} w^{\prime}\right\rangle \frac{\partial\langle u\rangle}{\partial z}\right\rangle d x d z .
\end{aligned}
$$

Similarly, the turbulence frictional dissipation rate $C_{d}$ was estimated using

$$
\begin{aligned}
C_{d}= & \frac{1}{A} \int_{-h}^{0} \int_{0}^{W}\left\langle u^{\prime}\left[\frac{\partial}{\partial z}\left(k_{m} \frac{\partial u}{\partial z}\right)\right]^{\prime}\right. \\
& \left.+v^{\prime}\left[\frac{\partial}{\partial z}\left(k_{m} \frac{\partial v}{\partial z}\right)\right]^{\prime}\right\rangle d x d z,
\end{aligned}
$$

where $w$ is the vertical velocity and $k_{m}$ is the eddy viscosity. The conversation rate from PE to EKE in Eq. (2.4) is also called the eddy buoyancy flux and it represents baroclinic instability. The conversion from MKE to EKE as a result of the horizontal and vertical current shear in Eq. (2.5) is an indication of barotropic and vertical shear instabilities, while the dissipation resulting from vertical mixing in Eq. (2.6) includes both bottom boundary and interior dissipation. Besides these energetic diagnostics, the alongshore decorrelation length scale $\lambda$ of the cross-shore velocity $u$ is estimated using a method similar to that described in B17. The autocovariance function (i.e., alongshore distance lag) of $u$ is calculated at a midshelf location ( $x=$ $55 \mathrm{~km})$ and at eight adjacent grid points spanning a cross-shore distance of $2 \mathrm{~km}$ (i.e., $54 \leq x \leq 56 \mathrm{~km}$ ). The calculations were carried out at three different vertical elevations $(z=0,-0.25 h$, and $-0.5 h)$ within the water column at the midshelf location and only at middepth $(z=-0.5 h)$ at the adjacent grid points. Then all these functions are averaged together. The decorrelation length scale $\lambda$ is assigned as the lag of the first zero crossing of the averaged function.

\section{Results}

Shelf circulation results for downwelling- and upwelling-favorable winds are presented separately here. The simulation results without baroclinic instabilities (no perturbation) represent wind-driven shelf circulation on a cooling shelf, which is uniform in the alongshore direction. These simulations are referred to as $2 \mathrm{D}$ runs. The results with baroclinic instabilities represent coupled baroclinic 
TABLE 1. List of model parameters, mean offshore $\overline{D_{1}}$ and onshore $\overline{D_{2}}$ depth limit of the inner-shelf outer boundary in 2D runs, EKE, and APE averaged over the last 50 days under both wind conditions.

\begin{tabular}{|c|c|c|c|c|c|c|c|c|c|}
\hline \multirow[b]{2}{*}{ Run } & \multirow[b]{2}{*}{$\alpha\left(\times 10^{-3}\right)$} & \multirow[b]{2}{*}{$|\tau|(\mathrm{Pa})$} & \multirow[b]{2}{*}{$B\left(\mathrm{~W} \mathrm{~m}^{-2}\right)$} & \multicolumn{4}{|c|}{ Downwelling } & \multicolumn{2}{|c|}{ Upwelling } \\
\hline & & & & $\overline{\overline{D_{1}}}(\mathrm{~m})$ & $\overline{D_{2}}(\mathrm{~m})$ & $\operatorname{EKE}\left(\times 10^{-3} \mathrm{~m}^{2} \mathrm{~s}^{-2}\right)$ & $\operatorname{APE}\left(\mathrm{J} \mathrm{m}^{-3}\right)$ & $\operatorname{EKE}\left(\times 10^{-3} \mathrm{~m}^{2} \mathrm{~s}^{-2}\right)$ & $\operatorname{APE}\left(\mathrm{J} \mathrm{m}^{-3}\right)$ \\
\hline 1 & 1.0 & 0.08 & -100 & 37.28 & 19.23 & 0.13 & 25.69 & 1.32 & 26.02 \\
\hline 2 & 1.0 & 0.08 & -50 & 44.47 & 20.75 & 0.08 & 24.50 & 0.86 & 21.09 \\
\hline 3 & 1.0 & 0.08 & -20 & 50.72 & 23.64 & 0.06 & 22.00 & 0.33 & 19.15 \\
\hline 4 & 1.0 & 0.04 & -100 & 25.34 & 12.84 & 0.63 & 17.02 & 2.73 & 24.89 \\
\hline 5 & 1.0 & 0.04 & -50 & 30.00 & 13.14 & 0.12 & 13.30 & 1.58 & 19.79 \\
\hline 6 & 1.0 & 0.04 & -20 & 31.98 & 14.39 & 0.03 & 9.86 & 0.51 & 9.88 \\
\hline 7 & 1.0 & 0.02 & -100 & 17.72 & 8.66 & 1.68 & 15.36 & 3.96 & 28.15 \\
\hline 8 & 1.0 & 0.02 & -50 & 19.66 & 8.20 & 0.88 & 10.47 & 2.46 & 21.05 \\
\hline 9 & 1.0 & 0.02 & -20 & 22.14 & 9.35 & 0.17 & 5.48 & 0.75 & 11.06 \\
\hline 10 & 0.75 & 0.08 & -100 & 36.04 & 18.67 & 0.18 & 31.22 & 1.54 & 30.44 \\
\hline 11 & 0.75 & 0.08 & -50 & 45.76 & 19.62 & 0.11 & 32.81 & 1.07 & 27.33 \\
\hline 12 & 0.75 & 0.08 & -20 & 53.74 & 27.08 & 0.08 & 28.45 & 0.07 & 26.53 \\
\hline 13 & 0.75 & 0.04 & -100 & 26.97 & 12.20 & 0.30 & 19.14 & 1.55 & 26.43 \\
\hline 14 & 0.75 & 0.04 & -50 & 24.44 & 12.64 & 0.08 & 17.68 & 1.13 & 21.42 \\
\hline 15 & 0.75 & 0.04 & -20 & 32.31 & 16.44 & 0.05 & 15.51 & 0.47 & 17.26 \\
\hline 16 & 0.75 & 0.02 & -100 & 18.32 & 8.54 & 0.94 & 15.96 & 2.59 & 26.46 \\
\hline 17 & 0.75 & 0.02 & -50 & 18.14 & 8.05 & 0.44 & 11.72 & 2.18 & 23.05 \\
\hline 18 & 0.75 & 0.02 & -20 & 20.42 & 9.05 & 0.08 & 7.57 & 0.66 & 13.62 \\
\hline 19 & 0.5 & 0.08 & -100 & 35.51 & 19.37 & 0.27 & 32.13 & 0.98 & 31.75 \\
\hline 20 & 0.5 & 0.08 & -50 & 38.23 & 22.04 & 0.24 & 37.68 & 0.42 & 33.92 \\
\hline 21 & 0.5 & 0.08 & -20 & 24.50 & 25.19 & 0.09 & 28.82 & 0.01 & 25.35 \\
\hline 22 & 0.5 & 0.04 & -100 & 25.55 & 12.84 & 0.14 & 21.75 & 1.21 & 24.39 \\
\hline 23 & 0.5 & 0.04 & -50 & 34.71 & 13.98 & 0.09 & 23.82 & 1.12 & 30.65 \\
\hline 24 & 0.5 & 0.04 & -20 & 16.96 & 16.20 & 0.09 & 22.48 & 0.10 & 24.75 \\
\hline 25 & 0.5 & 0.02 & -100 & 20.60 & 8.76 & 0.54 & 16.52 & 1.60 & 22.86 \\
\hline 26 & 0.5 & 0.02 & -50 & 20.32 & 7.86 & 0.11 & 14.12 & 1.36 & 25.18 \\
\hline 27 & 0.5 & 0.02 & -20 & & 8.82 & 0.05 & 12.19 & 0.26 & 22.10 \\
\hline 28 & 1.0 & 0.0 & -100 & & & 4.66 & 23.18 & & \\
\hline 29 & 1.0 & 0.0 & -50 & & & 3.50 & 17.52 & & \\
\hline 30 & 1.0 & 0.0 & -20 & & & 2.01 & 9.78 & & \\
\hline 31 & 0.75 & 0.0 & -100 & & & 4.37 & 22.23 & & \\
\hline 32 & 0.75 & 0.0 & -50 & & & 2.92 & 18.12 & & \\
\hline 33 & 0.75 & 0.0 & -20 & & & 1.68 & 11.67 & & \\
\hline 34 & 0.5 & 0.0 & -100 & & & 3.26 & 18.92 & & \\
\hline 35 & 0.5 & 0.0 & -50 & & & 2.64 & 19.87 & & \\
\hline 36 & 0.5 & 0.0 & -20 & & & 1.45 & 13.76 & & \\
\hline
\end{tabular}

instability and wind-driven shelf circulation processes; they exhibit a three-dimensional variability and are referred to as 3D runs. For these 3D runs, model energetics and cross-shore heat fluxes are also described.

\section{a. Downwelling-favorable winds $(\tau<0)$}

As uniform surface cooling is imposed on the initially homogeneous water, shallower water regions cool faster than deeper ones and a cross-shelf density gradient develops on the sloping shelf. Assuming a negligible crossshore heat flux due to horizontal convection and advection, the rate of temperature decrease and the associated cross-shore density gradient can be quantified using the linear equation of state (Pringle 2001; Horwitz and Lentz 2014):

$$
\begin{aligned}
& \frac{\partial T}{\partial t}=\frac{B}{\rho_{0} c_{p} h(x)}, \\
& \frac{\partial \rho}{\partial x}=\frac{\partial}{\partial x}\left[\rho_{0} \alpha_{T} \frac{B t}{\rho_{0} c_{p} h(x)}\right]=-\frac{\alpha_{T} B}{c_{p}}\left[\frac{\alpha t}{h(x)^{2}}\right],
\end{aligned}
$$

where $\alpha_{T}\left(=1.7 \times 10^{-4}{ }^{\circ} \mathrm{C}^{-1}\right)$ is the thermal expansion coefficient of seawater.

Figure 2 shows the simulated current velocity components and seawater temperature for both $2 \mathrm{D}$ and $3 \mathrm{D}$ runs $\left(\tau=-0.08 \mathrm{~Pa}, B=-50 \mathrm{~W} \mathrm{~m}^{-2}\right.$, and $\alpha=1.0 \times$ $\left.10^{-3}\right)$. Two sampling points in the water column, corresponding to $-2.0 \mathrm{~m}(\mathrm{P} 1)$ and $-31.0 \mathrm{~m}(\mathrm{P} 2)$ below the sea surface, are chosen to represent the upper and lower water layers, respectively. They are located in water depth of $35 \mathrm{~m}$, which is smaller than the vertical length 

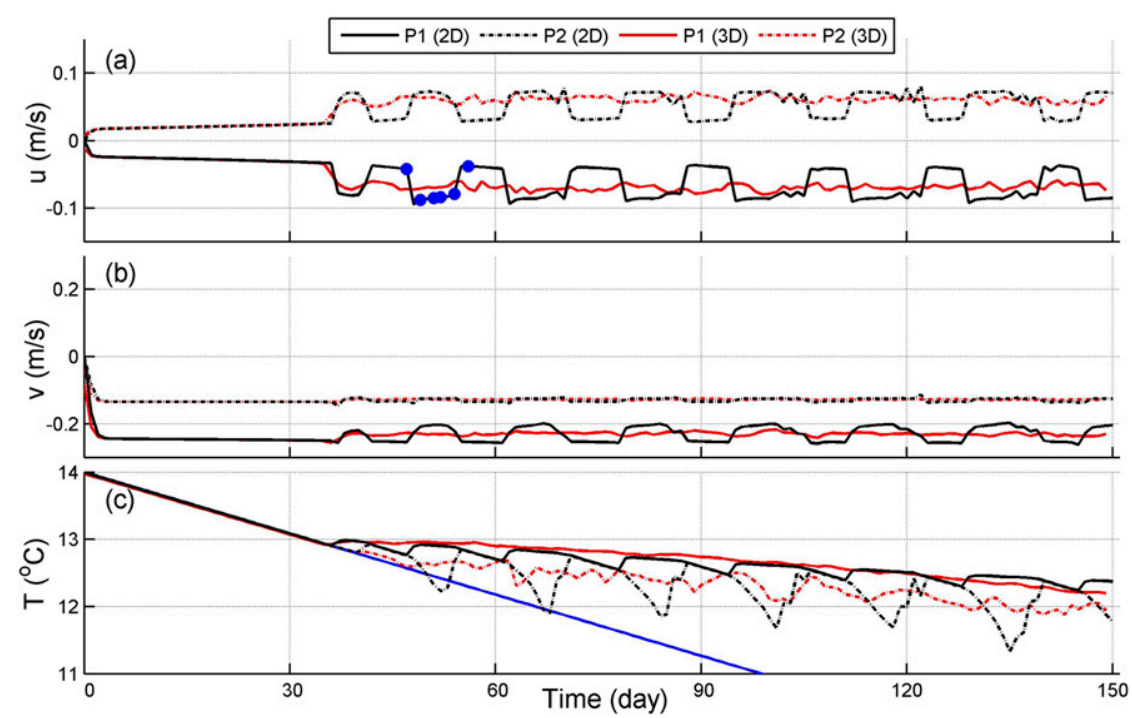

FIG. 2. Time series of (a) cross-shore velocity $u$, (b) alongshore velocity $v$, and (c) seawater temperature $T$ corresponding to points $\mathrm{P} 1$ (solid) and $\mathrm{P} 2$ (dashed) at a location of $35-\mathrm{m}$ water depth and at $2.0 \mathrm{~m}$ (near surface) and $30.8 \mathrm{~m}$ (near bottom) below the sea surface. Model results are from runs without instabilities (2D; black lines) and with instabilities (3D; alongshore averaged; red lines) with parameters as $\tau=-0.08 \mathrm{~Pa}, B=-50 \mathrm{~W} \mathrm{~m}^{-2}$, and $\alpha=1.0 \times 10^{-3}$. Blue circles in (a) correspond to the time steps shown in Fig. 3. The blue line in (c) shows the predicted temperature from Eq. (3.1).

scale $\delta_{\mathrm{Ek}}\left(=\kappa u^{*} / f\right)$ of $45.6 \mathrm{~m}$. For the 3D run, the flow velocities and seawater temperature are alongshore averaged to represent wind-driven circulation. These time series indicate that the temporal evolution of the flow can be divided into two stages that exhibit different characteristics (Fig. 2). During the first 35 days, a twolayer circulation pattern develops, where quasi-steady cross-shore currents flow in opposite directions in the upper and lower parts of the water column (Fig. 2a). Meanwhile, the temperature within both layers decreases linearly over time. The simulated rate of temperature decrease is accurately represented by Eq. (3.1), suggesting that during this stage (first 35 days), both cross-shore advection and convection are insignificant at this location. This appears to be the case for both 2D and $3 \mathrm{D}$ runs. Following this initial stage, the temporal variability of flow differs between the two runs. In the 2D run, a cyclic pattern develops with a periodicity of approximately 15 days. During each cycle, within both layers, the cross-shore current magnitude first increases and then decreases (Fig. 2a); the alongshore current magnitude shows a reversed pattern (Fig. 2b). For the 3D run, minimal flow fluctuations are seen in both surface and bottom layers. For both $2 \mathrm{D}$ and $3 \mathrm{D}$ runs, the temperature shows an overall decreasing trend over time in response to surface cooling. A temperature fluctuation is superimposed to the general trend that appears to be more pronounced in the bottom layer and of greater amplitude in the 2D run (Fig. 2c). This fluctuation seems to be coherent with the bottom current fluctuation, indicative of bottom advection.

The flow and density characteristics during the second stage (after day 35) are further examined in Fig. 3, where cross-shore sections of water temperature (colored contours), cross-shore velocity (vectors), alongshore velocity, and buoyancy frequency $N^{2}\left[=-\left(g / \rho_{0}\right)(\partial \rho / \partial z)\right]$ are shown. The selected time steps extend over a complete cycle (days 48-57) in the 2D run (Figs. 3a and 3b). For comparison purposes, the alongshore averaged results from the 3D run, for the same period, are also shown (see Fig. 3c). Surface cooling induces a cross-shore temperature gradient over the domain; in addition, a coastal jet and downwelling circulation develop in the alongshore and cross-shore directions, respectively (Fig. 3). For the 2D run, during the first 4 days of this cycle (see Fig. 3a), the nearshore colder water is transported offshore near the bed by the downwelling near-bottom flows. This leads to a tilting of the isopycnals, especially within the region with water depths of $20-40 \mathrm{~m}$. It enhances vertical stratification, leading to an increase of the cross-shore current magnitude (see Fig. 2a). These results are consistent with the findings in Horwitz and Lentz (2014), as the enhanced stratification suppresses turbulence and affects the current vertical shear. At day 52 [Fig. 3a(3)], a core of near-bottom cold water forms near the seabed and the alongshore jet shifts onshore. At day 53 [Fig. 3b(1)], 

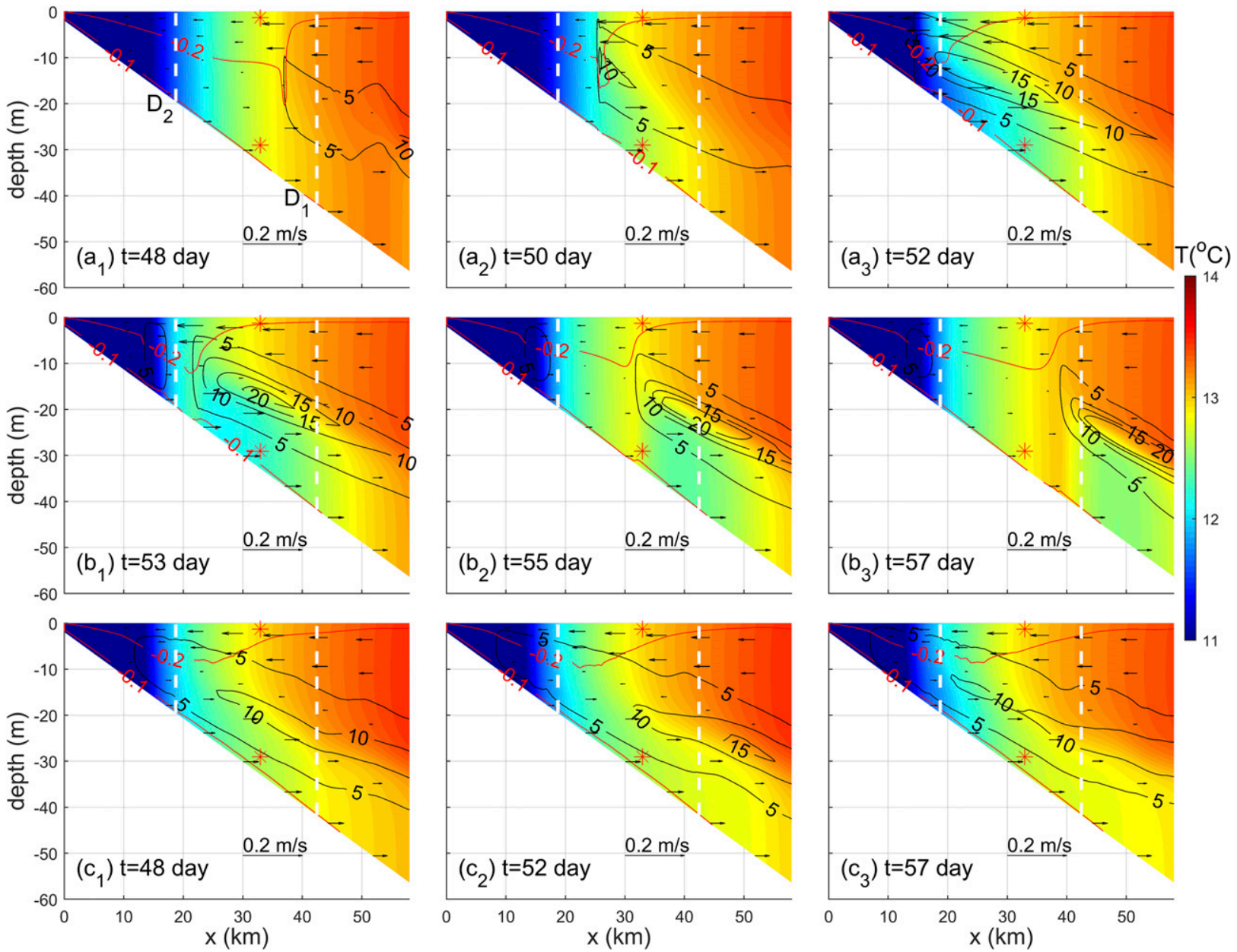

FIG. 3. Cross-shore sections of water temperature $T$ (filled color contours), buoyancy frequency $N^{2}=-\left(g \rho_{0}\right) \partial \rho / \partial z$ (black line contours; $\times 10^{-5} \mathrm{~s}^{-2}$ ), alongshore velocity (red line contour), cross-shore velocity vectors for the (a),(b) 2D and (c) 3D simulations. The upper and lower red asterisks show the locations of points P1 and P2, respectively, and the white dashed lines show the offshore $\left(D_{1}\right)$ and onshore $\left(D_{2}\right)$ limits of the inner-shelf outer boundary.

this core is detached from the adjacent cold water at $20-\mathrm{m}$ depth and it is exported downslope. The alongshore jet extends further offshore, and the cross-shore density gradient gradually returns to the same values as prior to the slumping of the isopycnals [Figs. $3 b(2)$ and $3 b(3)$ ]. In response, the shelf, at water depths of $20-40 \mathrm{~m}$, becomes less stratified and the cross-shore current decreases within this region (see Fig. 2a). Sustained surface cooling then rebuilds the cross-shore density gradient until another cycle takes place. This coupling of surface cooling and wind-driven $2 \mathrm{D}$ shelf circulation was also studied by Pringle (1998, see chapter 2 therein), who also observed the development of isopycnal slumping in response to a cross-shore density gradient (see Fig. 2.8 in Pringle 1998).

In contrast to the $2 \mathrm{D}$ run, in the $3 \mathrm{D}$ run the shelf remains well stratified over time; the cross-shore position of the alongshore jet barely varies, even though the stratification shows a slight variation of initial strengthening and then weakening during this cycle (Fig. 3c). Meanwhile, the two-layer cross-shore flow and the export of cold water fluctuate. The persistent stratification found in the 3D run is attributed to the continuous release of APE by the instabilities. Similar results were found in the study of wind effects on frontal instabilities within the surface mixed layer in the open ocean (Thomas and Ferrari 2008). In that study, the up-front wind (i.e., wind with a direction opposite to the geostrophic current shear) restratifies the surface mixed layer and inhibits instability formation.

As shown in Fig. 3, cross-shore current velocity fluctuations are present, especially within water depths $<40 \mathrm{~m}$, implying variability in Ekman transport within the inner shelf. Lentz (1995) used a method based on 

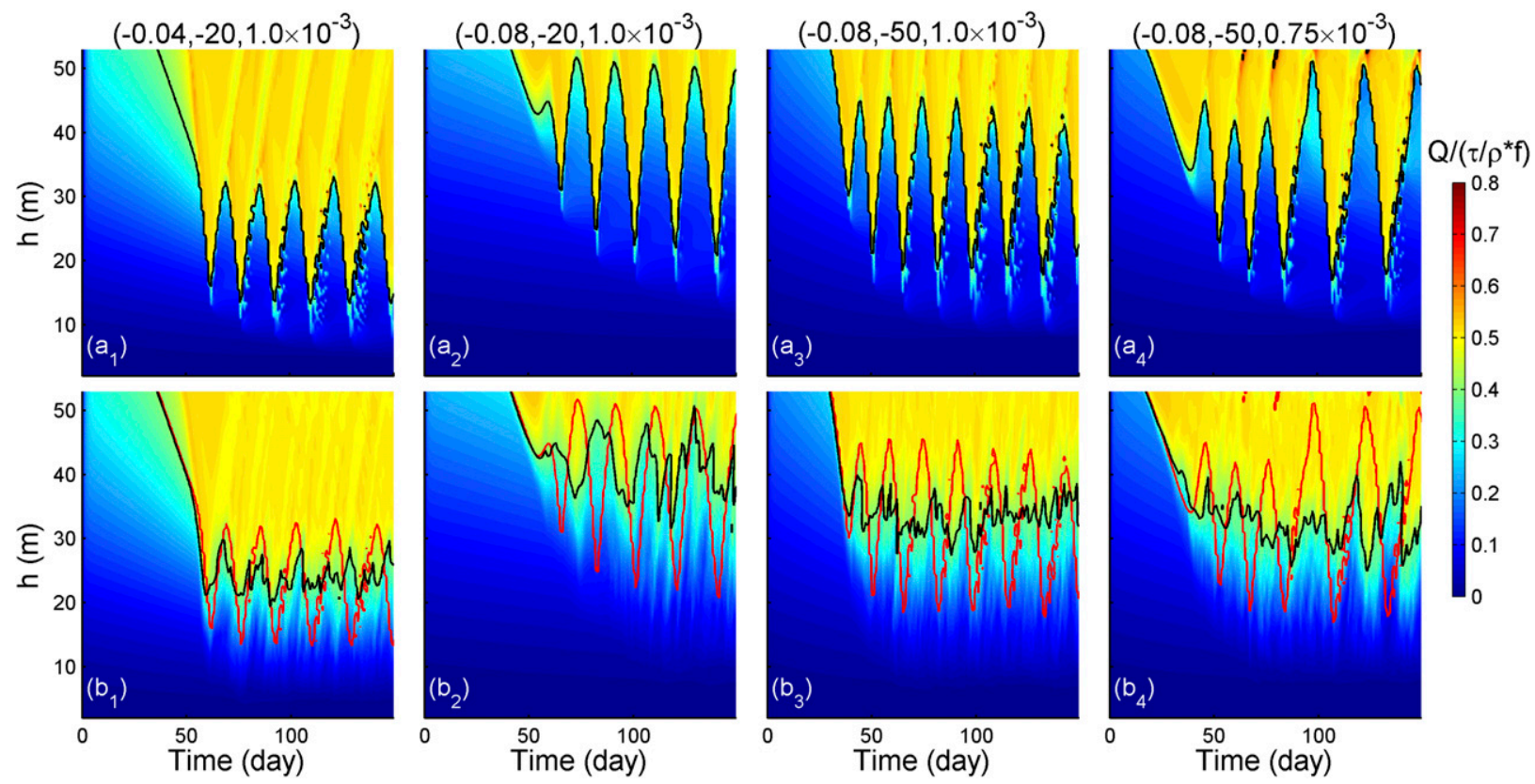

FIG. 4. Temporal and cross-shore (depth) variation of cross-shore Ekman transport $Q$ normalized by $\tau /\left(\rho_{0} f\right)$ for (a) $2 \mathrm{D}$ and (b) 3D model runs. The corresponding forcing conditions for each $2 \mathrm{D}$ or $3 \mathrm{D}$ run are (from left to right) $\tau=-0.04 \mathrm{~Pa}, B=-20 \mathrm{~W} \mathrm{~m}{ }^{-2}, \alpha=1.0 \times 10^{-3}$; $\tau=-0.08 \mathrm{~Pa}, B=-20 \mathrm{Wm}^{-2}, \alpha=1.0 \times 10^{-3} ; \tau=-0.08 \mathrm{~Pa}, B=-50 \mathrm{Wm}^{-2}, \alpha=1.0 \times 10^{-3} ;$ and $\tau=-0.08 \mathrm{~Pa}^{2} B=-50 \mathrm{Wm} \mathrm{m}^{-2}$, $\alpha=0.75 \times 10^{-3}$. The black line indicates the location of the maximum gradient; the red line in (b) (i.e., the 3D runs) is a replica of the corresponding contour from the $2 \mathrm{D}$ run shown in (a).

Ekman-layer thickness to define the inner shelf boundary, while Garvine (2004) and Austin and Lentz (2002) used the vertical and horizontal structures of water density, respectively. More recently, Horwitz and Lentz (2016) utilized the cross-shore structure of the Richardson number to define the boundary between the mid- and inner shelves. In this study, we utilize the location of the maximum cross-shore gradient of surface Ekman transport $Q$, as we found that it provides an effective delineation of the boundary between mid- and inner shelves, especially for the 2D runs. Surface Ekman transport $Q$ was calculated from the vertical integral of the positive (i.e., seaward) cross-shore currents within the water column. The temporal and spatial (in terms of cross-shore water depth) variability of its normalized value $Q^{\prime}=Q /\left[t /\left(\rho_{0} f\right)\right]$ is shown in Fig. 4. The location of the maximum $d Q^{\prime} / d x$ (cross-shore gradient of $Q^{\prime}$ ) in 2D runs is found to correspond to the location where $Q^{\prime}=0.4$ (Fig. 4a). During the first stage, the shallow shelf $(h<40 \mathrm{~m})$ is vertically homogeneous and the normalized Ekman transport is smaller than 0.4. Subsequently, stratification develops and the Ekmanlayer thickness decreases. For the 2D runs, the boundary between the mid- and inner shelves moves back and forth in a cyclic pattern. The maximum offshore and onshore water depths, which are related to cross-shore distances along the shelf slope, are denoted as $D_{1}$ and $D_{2}$, respectively. The time corresponding to when the midshelf-inner shelf boundary is at $D_{1}$ is defined as the onset of a cycle, and the period between the occurrences of two successive onsets defines a full cycle. Note that the values of $D_{1}$ and $D_{2}$ increase (deeper water depths) as the wind stress increases [see Figs. $4 \mathrm{a}(1)$ and $4 \mathrm{a}(2)$ ]. Increased heat loss rate [Figs. $4 \mathrm{a}(2)$ and $4 \mathrm{a}(3)$ ] reduces the duration of the first stage. It also tends to decrease the values of $D_{1}$ and $D_{2}$. For the 3D runs, the position of the boundary is less sharp. It fluctuates around the $D_{1}$ and $D_{2}$ values found in the 2D runs (see contour in Fig. $4 \mathrm{~b}$ ). As the wind stress increases in the 3D runs [Figs. $4 \mathrm{~b}(1)$ and $4 \mathrm{~b}(2)$ ], the variability of the boundary water depth tends to be less frequent. However, increased heat loss rate [Figs. $4 \mathrm{~b}(2)$ and $4 \mathrm{~b}(3)]$ tends to increase the frequency of the variability.

To further examine the evolution of the density field associated with each cycle, three parameters are used: (i) water temperature (referred to as mean temperature) averaged over a cross-shore section that extends laterally from depth $\overline{D_{1}}$ to $\overline{D_{2}}$, where $\overline{D_{1}}$ and $\overline{D_{2}}$ denote the mean values of $D_{1}$ and $D_{2}$ that are calculated from all the cycles of that run (see Table 1), respectively; (ii) cross-shore gradient of the depth-averaged density $\Delta \rho_{d} / \Delta x$ calculated between the locations corresponding to $\overline{D_{1}}$ and $\overline{D_{2}}$, where $\rho_{d}$ denotes the depth-averaged density; and (iii) $N_{m}^{2}$, defined as the value corresponding to the 95th percentile of the volumetrically cumulative distribution of $N^{2}$ over the same crossshore section arranged in an ascending order. The temporal 

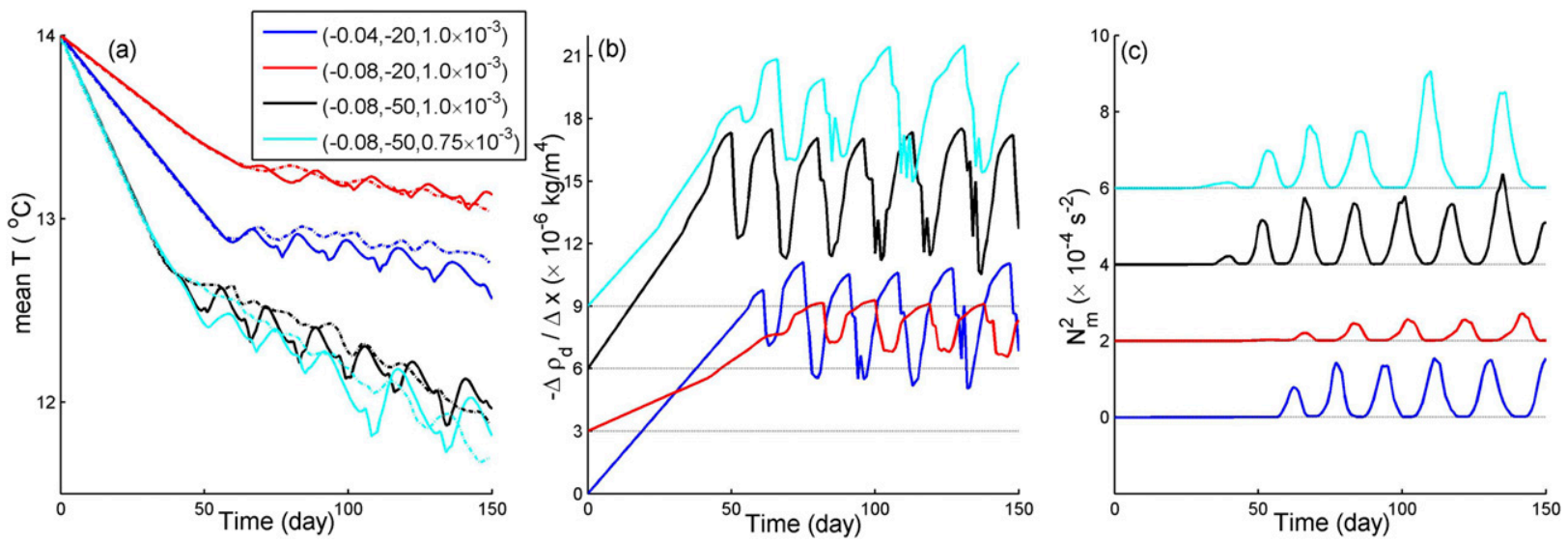

FIG. 5. Time series of (a) mean temperature $T$; (b) cross-shore density gradient $-\Delta \rho_{d} / \Delta x$; and (c) the top $5 \%$ cutting-off value of $N^{2}$ within the cross-shore section delineated by $\overline{D_{1}}$ and $\overline{D_{2}}$, where $\overline{D_{1}}$ and $\overline{D_{2}}$ are the averaged values of $D_{1}$ and $D_{2}$ over all the cycles detected from the corresponding run, and $\rho_{d}$ is the depth-averaged density. The four runs are the same as in Fig. 4. The dashed lines in (a) show the values from $3 \mathrm{D}$ runs in the same color. Note that the values are offset by an interval of (b) $3 \times 10^{-6} \mathrm{~kg} \mathrm{~m}^{-4}$ and (c) $2 \times 10^{-4} \mathrm{~s}^{-2}$.

evolution of each parameter is shown in Fig. 5. Once a cycle is triggered, the mean rate of temperature decrease (see Fig. 5a) is reduced, while an oscillatory deviation from this trend is superimposed onto the signal. Compared with the $2 \mathrm{D}$ runs, the mean temperature is slightly higher in the $3 \mathrm{D}$ runs. The cross-shore density gradient fluctuations show no trend of long-term change (Fig. 5b), and there seems to be a limit for the maximum value of the cross-shore density gradient. Within each cycle, $N_{m}^{2}$ first increases as the isopycnals slump, and then decreases as the detached near-bottom cold water is exported offshore (see Figs. 3a and 3b). Like the cross-shore density gradient, the values of $N_{m}^{2}$ do not seem to vary over longer time scales (Fig. 5c).

\section{b. Upwelling-favorable winds $(\tau>0)$}

Under upwelling-favorable wind conditions, the crossshore circulation pattern is significantly different from that described earlier in section $3 \mathrm{a}$. The negative cross-shore density gradient is effective in inhibiting wind-driven upwelling. As in Fig. 2, Fig. 6 shows the temporal variability of flow and temperature at points $\mathrm{P} 1$ and $\mathrm{P} 2$ for the $2 \mathrm{D}$ and $3 \mathrm{D}$ (alongshore averaged) runs, respectively, with forcing conditions of $\tau=0.08 \mathrm{~Pa}, B=-50 \mathrm{~W} \mathrm{~m}^{-2}$,

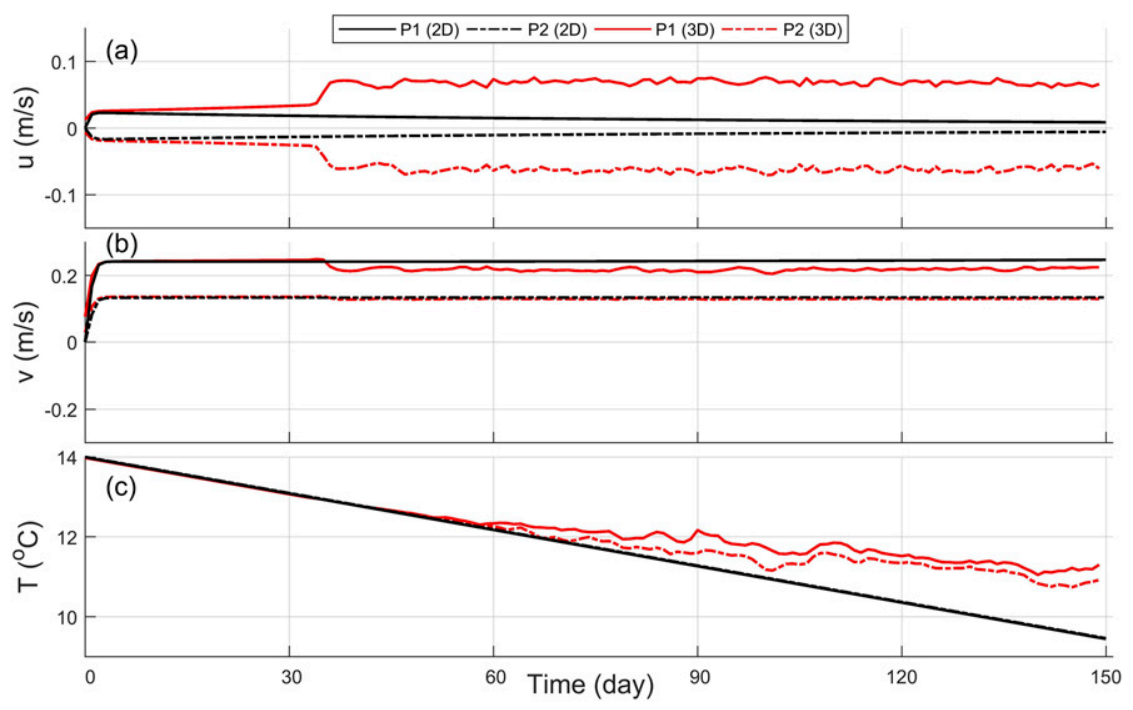

FIG. 6. Time series of (a) cross-shore velocity $u$, (b) alongshore velocity $v$, and (c) temperature $T$ at points $\mathrm{P} 1$ (solid line) and P2 (dashed line) for 2D (black) and 3D (red) runs with parameters $\tau=0.08 \mathrm{~Pa}, B=-50 \mathrm{~W} \mathrm{~m}^{-2}$ and $\alpha=1.0 \times 10^{-3}$. Locations of $\mathrm{P} 1$ and $\mathrm{P} 2$ are the same as in Fig. 2. 

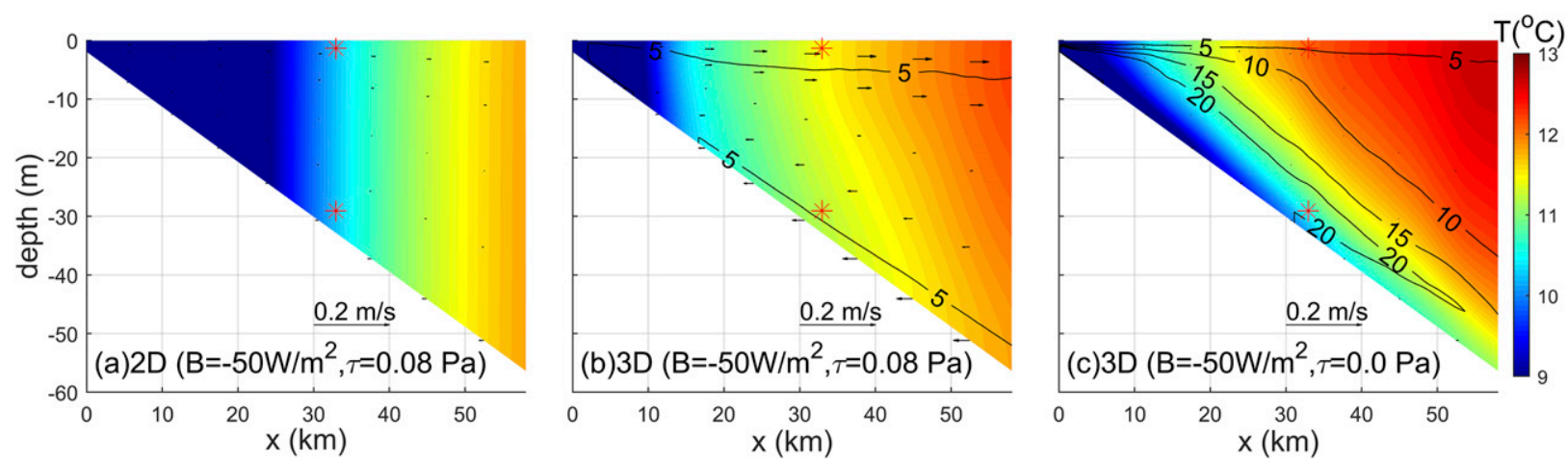

FIG. 7. Cross-shore sections of water temperature $T$ (filled color contours), buoyancy frequency $N^{2}$ (line contours; $\times 10^{-5} \mathrm{~s}^{-2}$ ), and cross-shore current vectors averaged over days 100-150 during (a) $2 \mathrm{D}$; (b) $3 \mathrm{D}$ runs with forcing $B=-50 \mathrm{~W} \mathrm{~m}^{-2}, \tau=0.08 \mathrm{~Pa}$; (c) $3 \mathrm{D}$ run with forcing $B=-50 \mathrm{~W} \mathrm{~m}^{-2}, \tau=0.0 \mathrm{~Pa}$. The upper and lower red asterisks show the locations of $\mathrm{P} 1$ and $\mathrm{P} 2$, respectively.

and $\alpha=1.0 \times 10^{-3}$. In the $2 \mathrm{D}$ run, the temperature at both points decreases linearly over time (Fig. 6c), in agreement with the predicted temperature decrease rate based on Eq. (3.1). Cross-shore circulation is effectively suppressed (Fig. 6a), as expected. For the 3D run, instability develops at day 35 , as it was the case in the simulation for the downwelling wind. The instability contributes to cross-shore heat flux, and the simulated temperatures at both $\mathrm{P} 1$ and $\mathrm{P} 2$ are higher than that found in the 2D run (Fig. 6c). Meanwhile, the alongshore current magnitude is slightly smaller than that in the 2D run and wind-driven upwelling can still develop on the stratified shelf (Figs. 6a and 6b).

Figure 7 shows cross-shore sections of temperature, buoyancy frequency $N^{2}$, and cross-shore currents, averaged over the last 50 days (days 100-150), for both the 2D and 3D (alongshore averaged) runs. This time represents the period when the instabilities have been fully developed in all the 3D runs. The 3D run results (alongshore averaged) corresponding to no-wind conditions are also shown for comparison (see Fig. 7c). As noted earlier, wind-driven circulation is suppressed in the $2 \mathrm{D}$ run (Fig. 7a). In the wind-driven 3D run (Fig. 7b), the cross-shore temperature gradient is still present and a small vertical stratification develops in response to the instabilities. However, the intensity of the vertical stratification is much weaker than that found in the results of the 3D run with no wind forcing (see Fig. 7c). In the latter case, strong vertical stratification develops over the shelf.

The evolution of the density field is further examined using the cross-shore gradient of $\rho_{d}$ for both the 2D and 3D (alongshore averaged) runs. Figure 8 shows the cross-shore distribution of the gradient for every 10 days during the last 50 days of the simulation and for water depths $<42 \mathrm{~m}$. At greater water depths, the cross-shore density gradient becomes too small to be accurately quantified and thus is not shown. The results are compared with the predictions from Eq. (3.2) that are shown as solid lines in Fig. 8. The simulated cross-shore density gradient in the $2 \mathrm{D}$ runs correlates well with the predictions, and the correlation coefficient $r$ reaches 0.98 . For the 3D runs, despite the high correlation coefficient $(r=0.90)$, the simulated cross-shore density gradient scatters around the predicted values (Fig. 8b). This variability is attributed to the instabilities, and the predicted values appear to provide the upper limit the density gradient can attain.

\section{c. Energy diagnostics}

B17 has shown that wind-driven downwelling tends to release APE and inhibits instabilities, while upwelling tends to supply additional APE and thus promotes them. Here, we focus on the effect of wind forcing on instabilities. Figure 9 shows the distribution of surface temperature, current vectors, and normalized relative vorticity $\zeta / f$ for the $3 \mathrm{D}$ runs under no-wind conditions and for both downwelling- and upwelling-favorable wind conditions. These results are for day 120, when instabilities have been fully developed. Under no-wind conditions [Figs. 9a(1) and 9b(1)], the surface currents are highly variable in space and high values of $\zeta / f$ are present both nearshore $(x<30 \mathrm{~km})$ and farther offshore $(x>30 \mathrm{~km})$, suggesting the development of eddies, as does the temperature field. In contrast, under downwelling or upwelling wind conditions [Figs. 9a(2), 9a(3), 9b(2), and $9 \mathrm{~b}(3)$ ], surface flows are mainly alongshore directed, and the $\zeta / f$ magnitudes are smaller than those found under no wind forcing. Similar results are also found in the simulations with different wind forcing values (not shown here).

The intensity of instability is further examined using the model energetics. The EKE budget is first presented here, and the results for the two 3D runs under downwelling- and upwelling-favorable wind conditions 

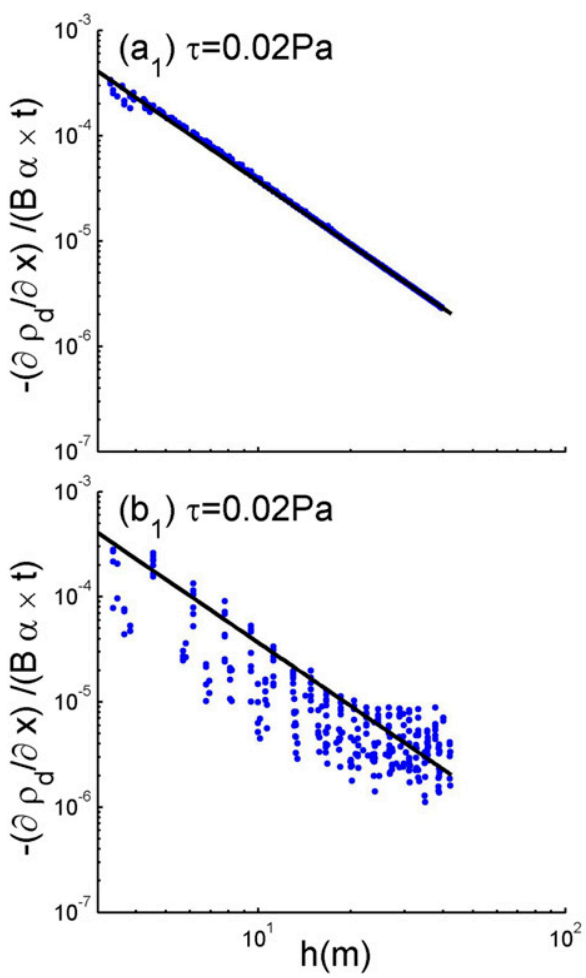
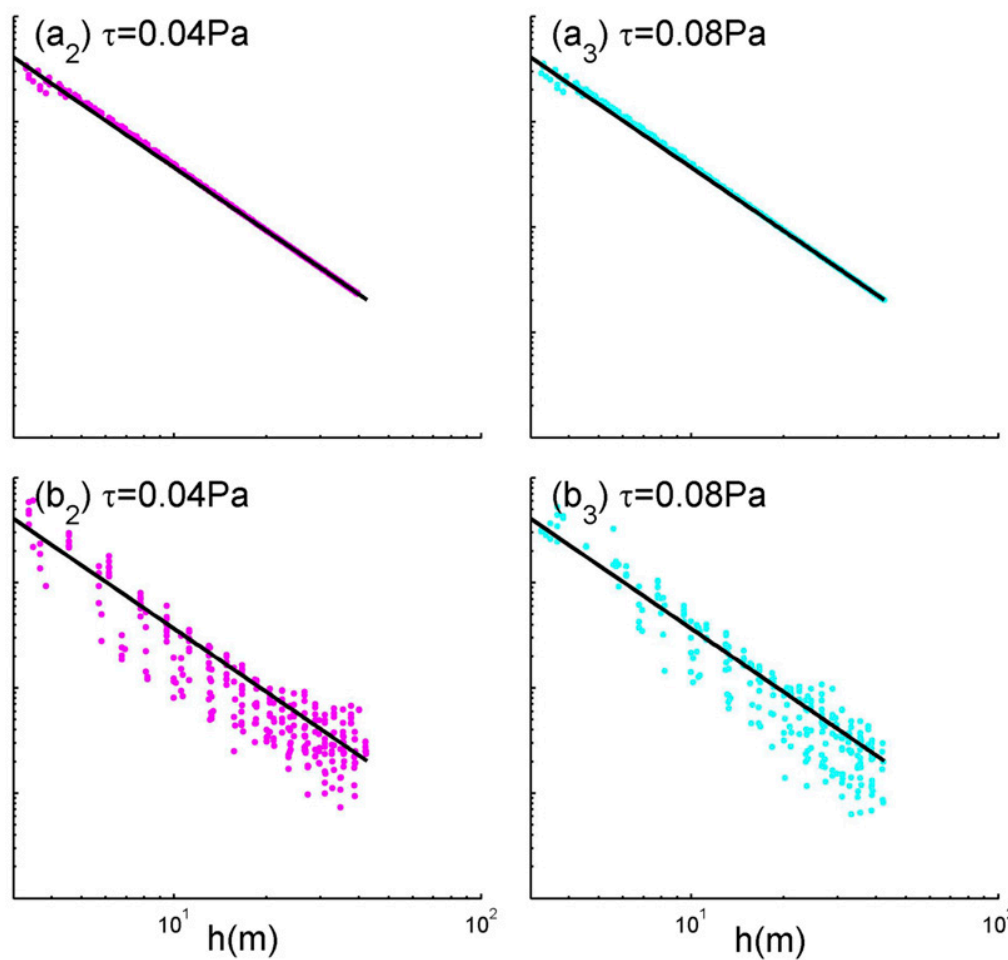

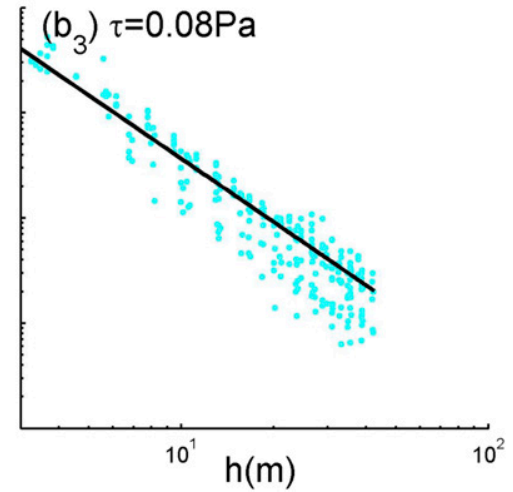

FIG. 8. Correlation between $-\left(\partial \rho_{d} / \partial x\right) /(B \alpha t)$ and depth $h$ in the cross-shore direction for all the (a) 2D and (b) 3D runs that have upwelling-favorable wind stress (from left to right) of 0.02, 0.04, and $0.08 \mathrm{~Pa}$. Black lines show the correlation predicted by using Eq. (3.2). The density gradient is calculated every 10 days during the last 50 days of each run and it is shown every 20 grid points in the cross-shore direction.

are shown in Fig. 10. All values are cross-shore averaged within the domain $x<55 \mathrm{~km}$. Similar patterns were obtained by extending the domain offshore to $x<80 \mathrm{~km}$. For both wind conditions, the eddy buoyancy flux $C_{\mathrm{sp}}$ is the primary source term and it is much bigger than the secondary source $C_{\mathrm{sk}}$. The sum of these two terms is roughly balanced by the EKE dissipation term $C_{d}$, a pattern consistent with the findings of B17. However, the secondary role of $C_{\mathrm{sk}}$, under upwelling conditions does not agree with Thomas and Taylor (2010), who found $C_{\text {sk, }}$ to be the primary source. In that study, the down-front wind (i.e., wind directed along the geostrophic shear) in the open ocean extracts Ertel's potential vorticity from the ocean fronts and this favors the development of symmetrical instabilities within the surface mixed layer. Symmetrical instabilities extract kinetic energy through geostrophic shear production and thus the term $C_{\text {sk }}$ acts as the primary source (Taylor and Ferrari 2010; Thomas and Taylor 2010). In our simulations, Ertel's potential vorticity remains positive on the shelf and no symmetrical instabilities are detected.

The distributions of the volume-averaged EKE, APE, eddy buoyancy flux $C_{\mathrm{sp}}$, turbulence frictional dissipation $C_{d}$, and the alongshore decorrelation length scale $\lambda$ in relation to wind stress are shown in Fig. 11 for all the $3 \mathrm{D}$ runs. The first four variables are cross-shore averaged within the domain $x<55 \mathrm{~km}$, and all variables are temporally averaged over the last 50 days of the simulations, when instabilities have been fully developed. Under downwelling wind conditions $(\tau<0)$, EKE rapidly decreases as the magnitude of wind stress increases (Fig. 11a), as reported in B17. Under upwelling-favorable wind conditions $(\tau>0)$, a decrease of EKE is also seen as the magnitude of the wind stress increases (Fig. 11a), but the rate of decrease is smaller than that found for the downwelling cases. This decrease of EKE is opposite of the results in B17, where a slight enhancement of EKE was observed for upwelling winds. However, the reduction of EKE in our results seems to agree with the findings of Rogers-Cotrone et al. (2008), who studied wind effects on river plumes. That study demonstrated that an increase of downwelling-favorable wind inhibits plume instabilities and decreases the eddy flux of freshwater. It should be noted that cross-shore density gradient in the plumes in RogersCotrone et al. (2008) is opposite of that considered here.

In addition to EKE, APE values show a different rate of change in relation to wind stress (Fig. 11b) for downwelling and upwelling conditions. In the former case, APE first 


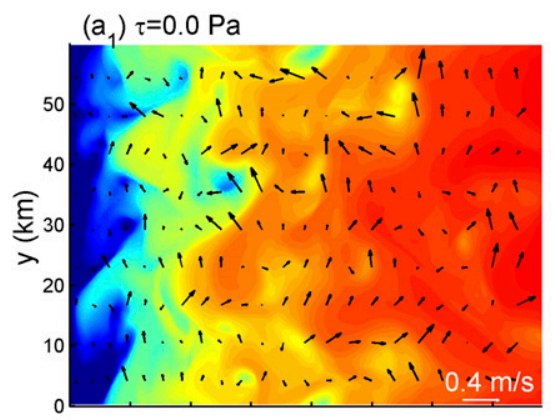

$\left(b_{1}\right) \tau=0.0 \mathrm{~Pa}$

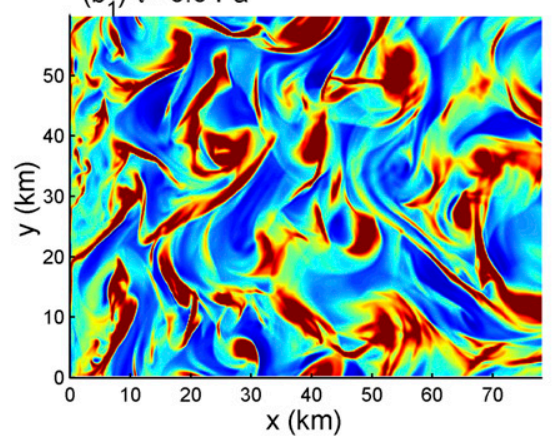

$\left(\mathrm{a}_{2}\right) \tau=-0.04 \mathrm{~Pa}$

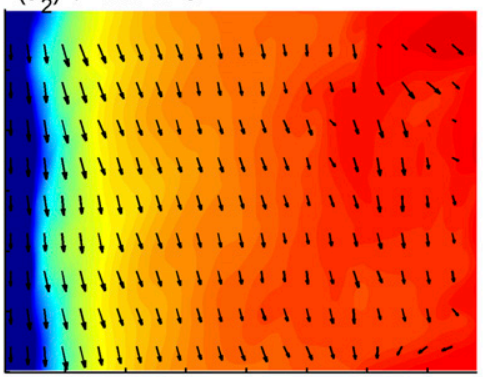

$\left(b_{2}\right) \tau=-0.04 \mathrm{~Pa}$

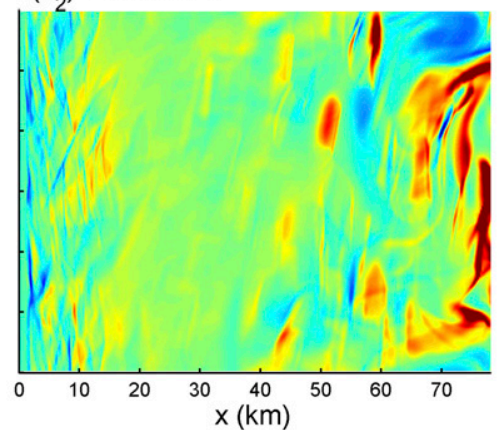

$\left(\mathrm{a}_{3}\right) \tau=0.04 \mathrm{~Pa}$

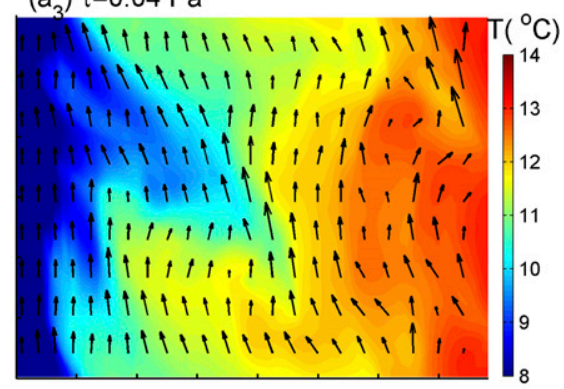

$\left(\mathrm{b}_{3}\right) \tau=0.04 \mathrm{~Pa}$

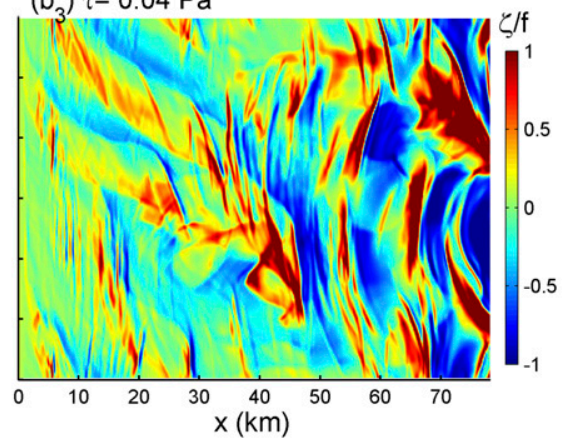

FIG. 9. (a) Surface temperature (filled color contours) and current vectors and (b) the normalized relative vorticity $\zeta / f$ at the surface at day 120 for the 3D model runs with parameters $\alpha=1.0 \times 10^{-3}, B=-50 \mathrm{~W} \mathrm{~m}^{-2}$, and (left to right) $\tau=0.0,-0.04$, and $0.04 \mathrm{~Pa}$.

decreases and then increases as the magnitude of wind stress increases. Under upwelling winds, APE generally increases as the wind stress increases. Overall, the decrease of EKE for upwelling conditions is associated with an increase of APE, which is reasonable considering that the sustained surface cooling provides the APE consumed by the instabilities. However, this is not the case for downwelling conditions. APE values decrease at low wind stress values (i.e., $\tau=-0.02 \mathrm{~Pa}$ ), as the wind alone can effectively export the nearshore cold water through the development
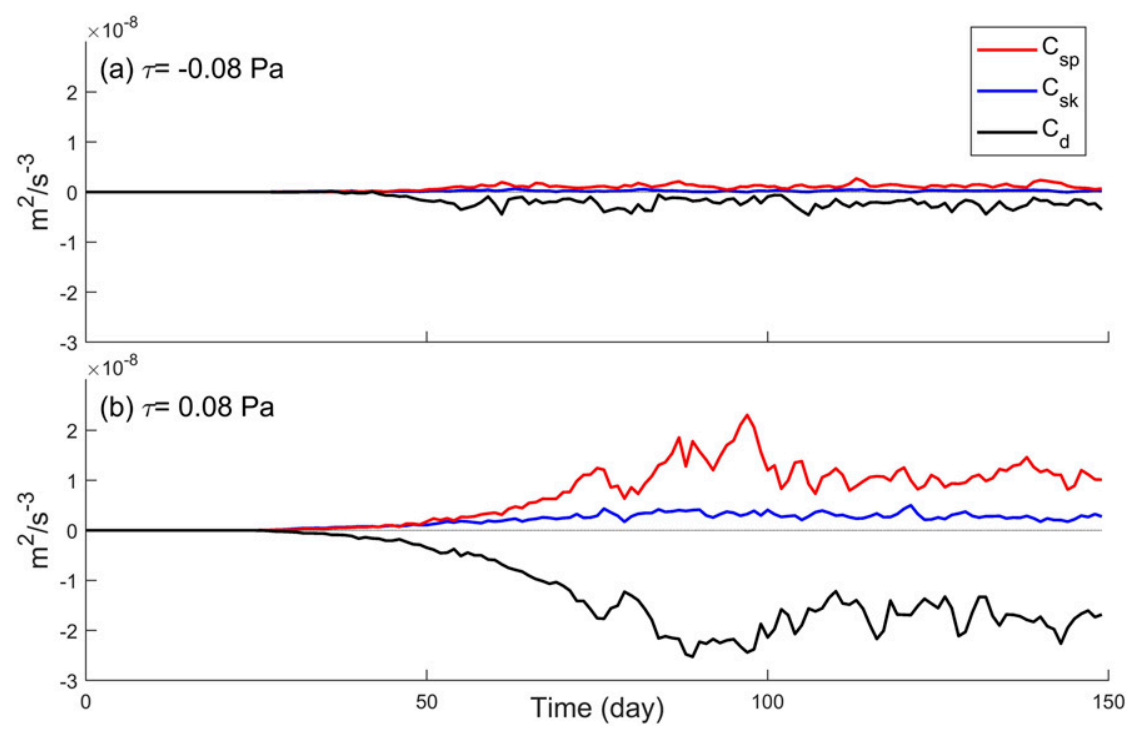

FIG. 10. Time series of eddy buoyancy flux $C_{\text {sp }}$, the conversion from MKE to EKE caused by barotropic instability and vertical shear instability $C_{\mathrm{sk}}$, and the EKE dissipation caused by eddy turbulence $C_{d}$ for the 3D runs with parameters $\alpha=1.0 \times 10^{-3}, B=-50 \mathrm{~W} \mathrm{~m}^{-2}$, and (a) $\tau=$ -0.08 and (b) $\tau=0.08 \mathrm{~Pa}$. 

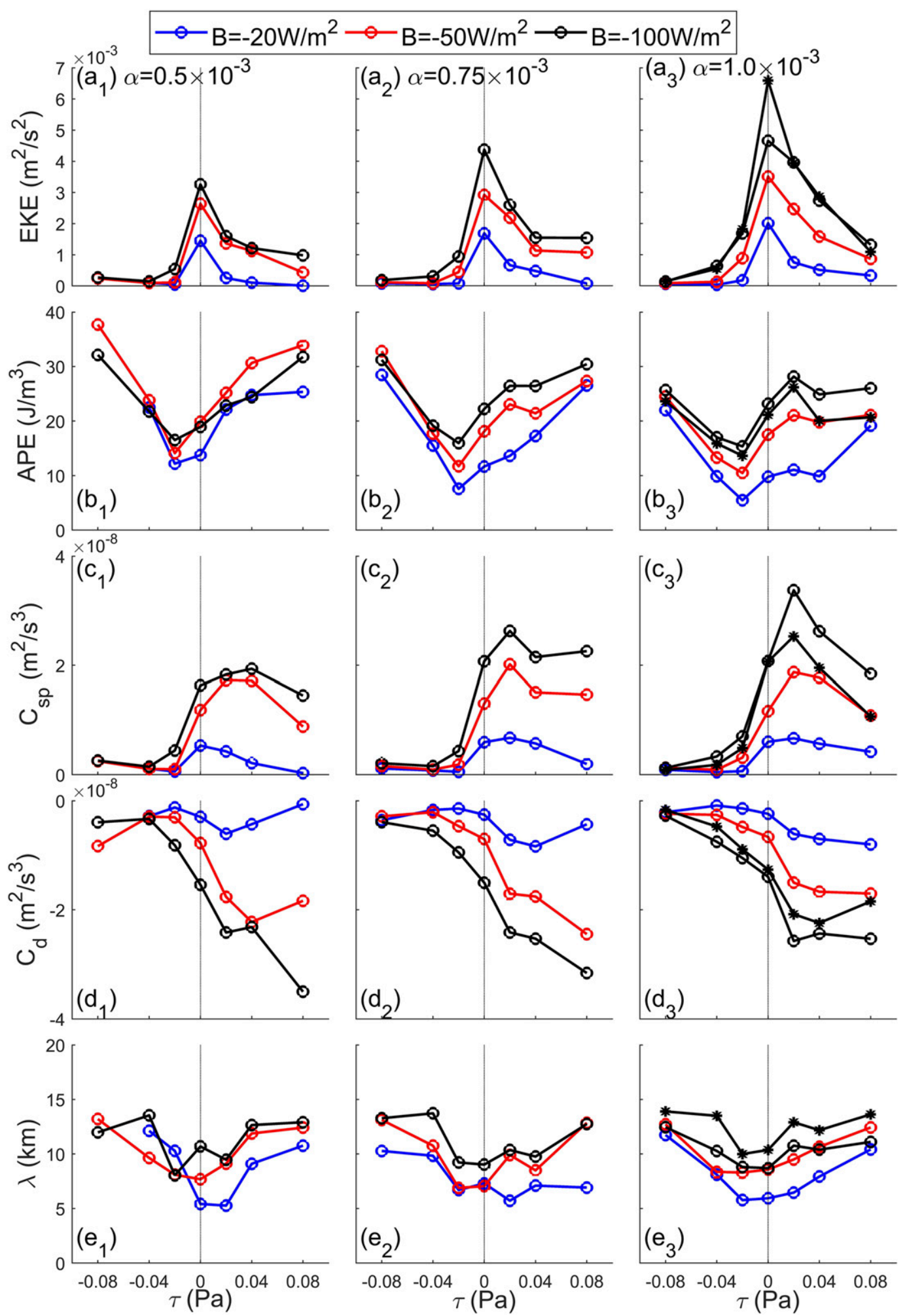

FIG. 11. Change of volume-averaged (a) EKE, (b) APE, (c) eddy buoyance flux $C_{\text {sp }}$, (d) turbulence frictional dissipation $C_{d}$, and (e) the alongshore decorrelation length scale $\lambda$, as the wind stress changes in the 3D runs with (left to right) $\alpha=0.5 \times 10^{-3}, 0.75 \times 10^{-3}$, and $1.0 \times 10^{-3}$. All parameters are the averaged values during the last 50 days of each run, a period that experiences fully developed instability. The black line with asterisks in the right column shows the results in the runs with $z_{0}=0.01 \mathrm{~cm}$ and $B=-100 \mathrm{~W} \mathrm{~m}^{-2}$. 
of a thin Ekman layer. In addition to wind stress, an increase in heat loss rate magnitude tends to increase APE.

The change of $C_{\mathrm{sp}}$ and $C_{d}$ in relation to wind stress is also shown in Figs. 11c and 11d. Under downwelling conditions, the magnitudes of both terms rapidly decrease with increasing wind speed. In contrast, under upwelling conditions, $C_{\mathrm{sp}}$ first increases and then decreases as the wind speed increases, while the magnitude of $C_{d}$ shows an overall increasing trend. The larger $C_{d}$ found under upwelling conditions is attributed to the shelf being more barotropic (see Figs. 3c and 7b), so the flow is more affected by bottom friction. The overall smaller magnitudes of $C_{d}$ under downwelling conditions indicate that the rapid decrease of EKE is mainly because of limited availability of the source term $C_{\mathrm{sp}}$. However, under upwelling conditions, EKE dissipation $C_{d}$ becomes dominant and leads to an inhibition of the instabilities as wind speed increases. This result is consistent with the findings in Rogers-Cotrone et al. (2008), where increasing of the downwelling-favorable wind enhances the EKE dissipation and constrains plume instability.

Wind forcing also affects the alongshore decorrelation length scale $\lambda$ (see Fig. 11e). For both wind directions, as wind speed increases, $\lambda$ tends to increase and this indicates that the cross-shore current is less disrupted by instabilities. This agrees with the decreasing trend of EKE as wind speed increases for both wind directions. The increasing trend of $\lambda$ is different from the findings in B17, which showed a slight decrease of $\lambda$ as wind speed increases.

The sensitivity of the energy flux to bottom friction is also examined [see the black lines with asterisks in Figs. 11a(3), 11b(3), 11c(3), 11d(3), and 11e(3)] through a comparison of results from two simulations with identical wind forcing and heat loss rate but different roughness $\left(z_{0}=1.0 \mathrm{vs} 0.01 \mathrm{~cm}\right)$. As in B17, our analysis shows that bottom friction has no significant effect on EKE [Fig. 11a(3)], but the magnitude of $C_{d}$ decreases slightly as bottom friction decreases [Fig. 11d(3)]. This decrease in dissipation is associated with a decrease in the source term $C_{\mathrm{sp}}$ [see Fig. 11c(3)]. A slight decrease of APE and an increase of the alongshore decorrelation length scale are also found as bottom friction decreases [Figs. 11b(3) and 11e(3)].

\section{d. Cross-shore heat flux}

Eddy and mean cross-shore heat fluxes were calculated within the same cross-shore section and period used for the estimation of volume-averaged EKE (Fig. 12). Under downwelling conditions, as wind speed increases, the magnitude of eddy heat flux decreases; meanwhile, the mean heat flux initially increases and then decreases. The total heat flux value is dominated by the mean component, consistent with the findings in B17. For upwelling conditions, although the magnitude of eddy heat flux is bigger than that of the mean heat flux, both terms are important to the total heat flux. These results are slightly different from the results presented in B17, where the mean heat flux was found to become strikingly less important under upwelling conditions. Finally, bottom roughness does not appear to affect the mean heat flux, while the eddy heat flux tends to slightly decrease under smaller bottom roughness, especially under upwelling conditions [Figs. 12a(3) and 12b(3)].

\section{Discussion}

In this section the results of the $2 \mathrm{D}$ and $3 \mathrm{D}$ runs are used to better understand the interactions between wind forcing and instabilities. Furthermore, the qualitative description of the results presented in the previous sections is placed into context relative to realistic oceanic conditions.

\section{a. Cross-shore density gradient}

In the absence of instabilities (i.e., 2D runs), the temporal evolution of the density field under upwelling conditions is primarily controlled by vertical convection as verified by the agreement between model runs and the theoretical prediction [see Eq. (3.2)]. However, during the second stage, under downwelling conditions, the observed cross-shore density gradient fluctuation (see Fig. 5) is not predicted by Eq. (3.2). The cross-shore distribution of $\partial \rho_{d} / \partial x$ at the onset of each cycle (the critical density gradient) and within the depth ranges defined by $D_{1}$ and $D_{2}$ is further examined below.

Cross-shore pressure gradient at vertical level $z$ can be expressed as a function of cross-shore density gradient using

$$
-\frac{1}{\rho_{0}} \frac{\partial p(z)}{\partial x}=-g \frac{\partial \eta}{\partial x}-\frac{g}{\rho_{0}} \frac{\partial}{\partial x} \int_{-h(x)}^{z} \rho z^{\prime} d z^{\prime}
$$

where $\eta$ is the sea surface level. Surface cooling temporally increases cross-shore density gradient and thus cross-shore pressure gradient. Under downwelling conditions, the latter is always balanced by the Coriolis forcing. Here we assume that the cycle in the $2 \mathrm{D}$ runs is trigged once the cross-shore pressure gradient (or the density gradient) reaches a critical value above which it cannot be balanced by the Coriolis forcing. In the following we aim to quantify this critical value.

The cooling-induced positive (seaward directed) crossshore density gradient could induce a positive vertical current shear (i.e., $\partial v / \partial z>0$ ) in the alongshore direction. This is supported by the results from the no-wind forcing runs, where a mean positive alongshore current develops. Using Eq. (3.2) and assuming a thermal wind balance 


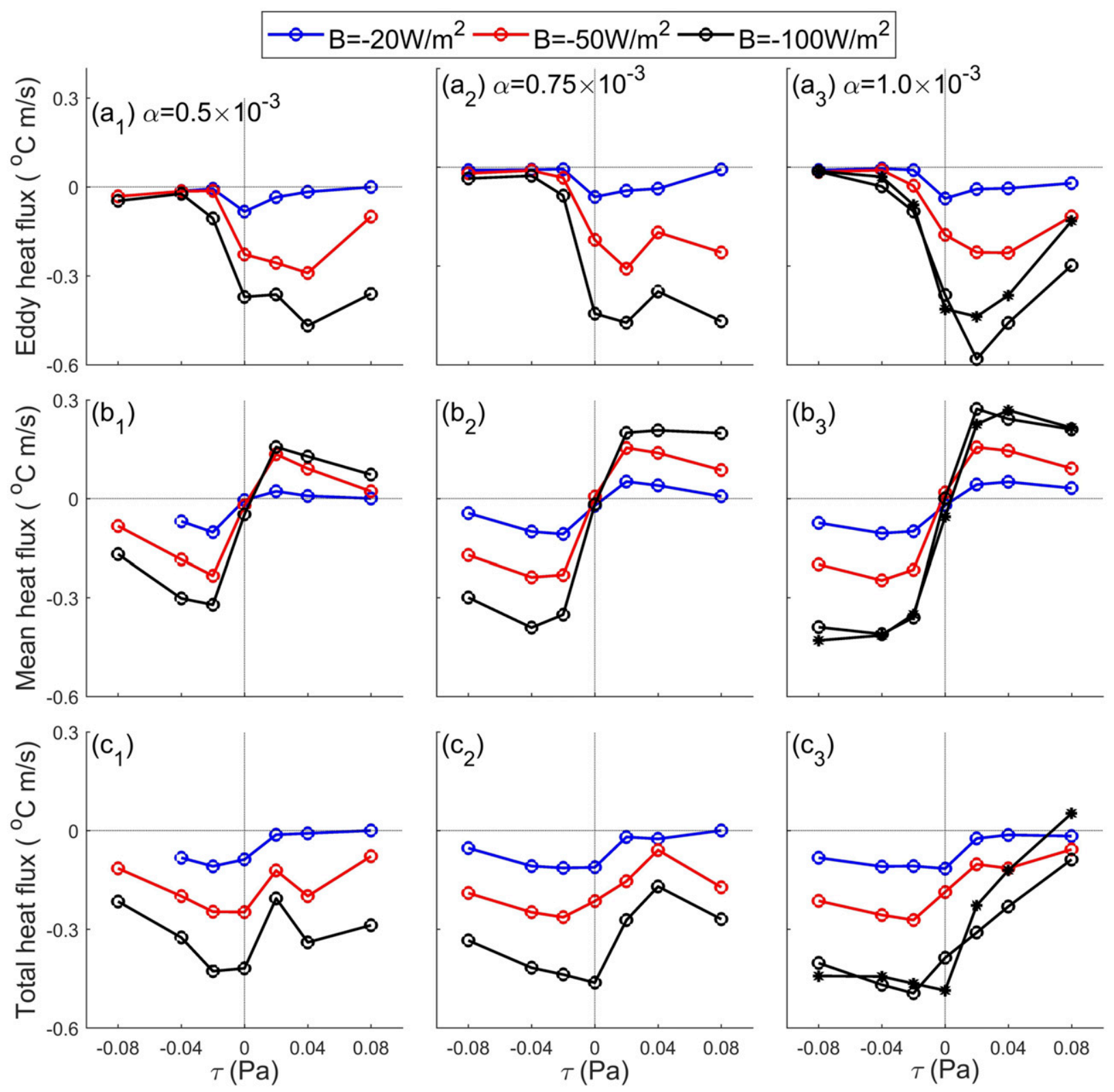

FIG. 12. Change of (a) eddy, (b) mean, and (c) total heat flux, as the wind stress changes in the 3D runs with (left to right) $\alpha=0.5 \times 10^{-3}$, $0.75 \times 10^{-3}$, and $1.0 \times 10^{-3}$. All parameters are the averaged values during the last 50 days of each run. The black line with asterisks in the right column shows the results in the runs with $z_{0}=0.01 \mathrm{~cm}$ and $B=-100 \mathrm{~W} \mathrm{~m}^{-2}$.

relationship, the cooling induced current shear can be estimated as

$$
\left.\frac{\partial v}{\partial z}\right|_{\text {cool }}=-\frac{g \alpha_{T} B}{f c_{p}}\left[\frac{\alpha t}{h(x)^{2}}\right] .
$$

This vertical current shear and the associated cross-shore flows are opposite of those induced by downwelling-favorable winds only. If we assume that the wind-induced surface current velocity can be approximated as $v=\tau /\left(\rho \sqrt{f k_{m}}\right)$ (assuming Ekman theory), then the wind-induced current shear can be expressed as

$$
\left.\frac{\partial v}{\partial z}\right|_{\text {wind }}=a_{1} \frac{\tau}{\rho \sqrt{f k_{m}} h(x)}
$$

where $a_{1}$ is a constant. Here, we further assume that the first cycle is triggered at time $t_{m}$ when the critical cross-shore density gradient is reached and the cooling-induced 
current shear is balanced by the wind-induced shear at water depth $h_{c}$. The time $t_{m}$ can be derived as

$$
t_{m}=\frac{a_{1} f c_{p} \tau h_{c}}{g \sqrt{f k_{m}} \alpha_{T} \alpha B} .
$$

Substituting Eq. (4.4) into Eq. (3.2), the cross-shore distribution of the critical cross-shore density gradient at time $t_{m}$ can be obtained using

$$
\left.\frac{\partial \rho_{d}}{\partial x}\right|_{t=t_{m}}=\frac{a_{1} f \tau h_{c}}{g \sqrt{f k_{m}} h(x)^{2}} .
$$

It is worth noting that the equation above does not include the heat loss rate $B$. As shown in Eq. (4.2), the cooling-induced current shear is determined by the value of the total heat loss, which is defined by the product $B t$. Equation (4.5) defines the critical density gradient at time $t_{m}$, which in turn depends on the value of $B$. Under downwelling-favorable winds, the development of cross-shore flows (see Fig. 3) can lead to cross-shore density advection. This can be the case for simulations with a smaller magnitude of $B$, as a longer $t_{m}$ is required to achieve the same total heat loss. To account for this wind-driven cross-shore advection, an arbitrary empirical correction factor $\left(B / B_{0}\right)^{\gamma}$ is introduced, where $B_{0}$ is a constant heat loss rate and $\gamma$ is a constant. The resulting cross-shore density gradient is expressed as

$$
\left.\frac{\partial \rho_{d}}{\partial x}\right|_{t=t_{m}}=\left(\frac{B}{B_{0}}\right)^{\gamma} \frac{a_{1} f \tau h_{c}}{g \sqrt{f k_{m}} h^{2}}=a_{2} \frac{\sqrt{f}|B|^{\gamma} \tau}{\left|B_{0}\right|^{\gamma} g h(x)^{2}},
$$

where $a_{2}=a_{1} h_{c} / \sqrt{k_{m}}$ is a dimensional quantity $\left(\mathrm{s}^{1 / 2}\right)$. Assuming that $a_{2}$ is a constant, the rhs of Eq. (4.6) can be used to quantify the cross-shore distribution of $\partial \rho_{d} / \partial x$ at the onset of each cycle. A least squares fitting regression analysis is performed using the values obtained at the onset of each cycle recorded in all 2D runs (Fig. 13). It results in $\gamma=0.43$ and a correlation coefficient of 0.99 . Close to depth $D_{1}$, the cross-shore density gradient becomes very small and there is a bias, especially for the case $\tau=-0.08 \mathrm{~Pa}$. During the second stage of all 2D runs, Eq. (4.6) quantifies the maximum cross-shore density gradient attained before it is converted into the vertical density gradient (see Fig. 3a). This maximum density gradient is what was defined earlier as the critical value. Above this value, the positive (seaward directed) cross-shore baroclinic pressure gradient may become unbalanced by the Coriolis forcing associated with the wind-driven flow. Thus, an offshore export of the dense water develops.

Instabilities in the 3D runs enhance vertical stratification. Once the instabilities develop, the shelf remains

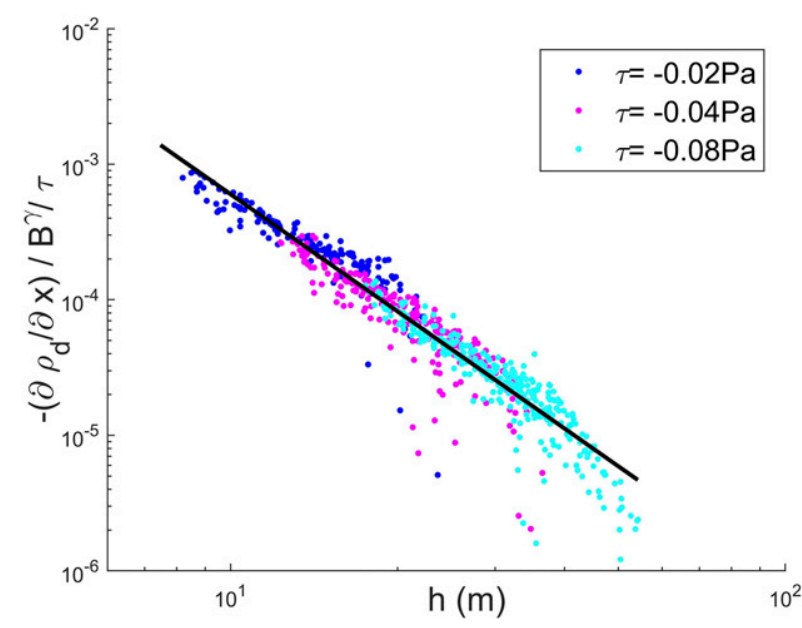

FIG. 13. Logarithmic fitting of $-\left(\partial \rho_{d} / \partial x\right) /\left(B^{\gamma} \tau\right)$ as a function of depth $h$ for all the $2 \mathrm{D}$ runs under downwelling conditions. The density gradient $\partial \rho_{d} / \partial x$ is calculated at the onset of each cycle of the $2 \mathrm{D}$ runs, and the depth is within the range of $\left(D_{1}, D_{2}\right)$ detected within each cycle.

well stratified and the cyclic pattern shown in the $2 \mathrm{D}$ runs is not fully developed (see Fig. 3c). Instead, the position of the offshore boundary of the inner shelf oscillates irregularly in the cross-shore direction (see Fig. 4b). The cross-shore density gradient $\Delta \rho_{d} / \Delta x$ in the $3 \mathrm{D}$ runs (not shown here) also fluctuates but its amplitude is always smaller than that shown in Fig. $5 b$ for the $2 \mathrm{D}$ runs. The combination of the instabilities and winddriven downwelling flow leads to a more effective export of the colder coastal water than that achieved through the cyclic pattern found in the $2 \mathrm{D}$ runs. This enhanced cross-shore heat flux is evident in the higher water temperature seen in the $3 \mathrm{D}$ run results (see examples in Figs. 2c and 5a).

Under upwelling conditions, the cross-shore density gradient in the 2D runs is solely controlled by surface cooling. In the 3D runs, wind-driven upwelling can develop, which in turn restrains the offshore export of near-bottom cold water. The net seaward export of dense water induced by instabilities results in higher temperatures nearshore in this case (see Fig. $6 \mathrm{c}$ for an example).

\section{b. Variability of the inner shelf extent}

Under downwelling conditions, the cross-shore extent of the inner shelf varies temporally. Here we attempt to quantify the variation of the inner shelf extent in $2 \mathrm{D}$ runs first and then discuss the factors that can affect the variations found in the $3 \mathrm{D}$ runs.

For the 2D runs, once the boundary of the inner shelf reaches depth $D_{2}$, the vertical density gradient reaches its maximum value, which can be expressed through the 

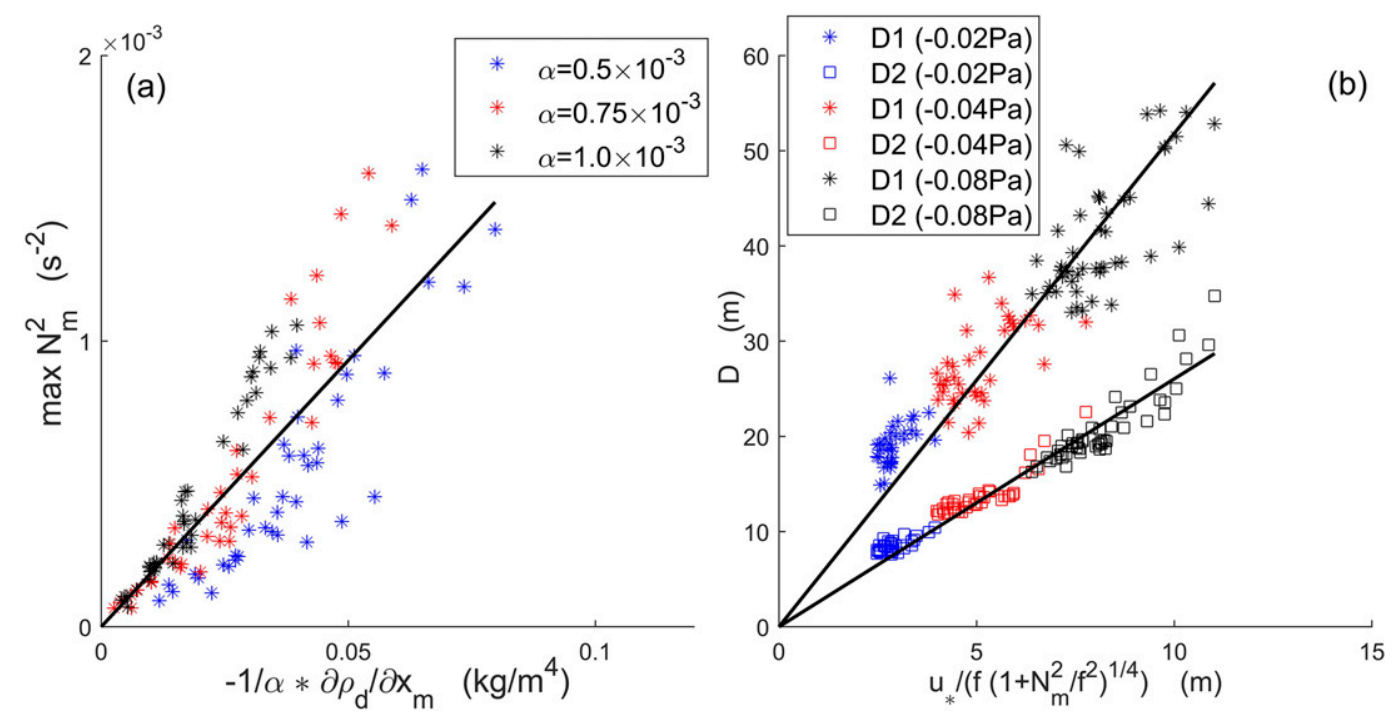

FIG. 14. (a) Correlation between the maximum $N_{m}^{2}$ during each cycle and $-(1 / \alpha)\left(\Delta \rho_{d} / \Delta x\right)$ in all the $2 \mathrm{D}$ runs. (b) Fitting of the depth of the inner-shelf outer boundary $D_{1}$ (asterisks) and $D_{2}$ (squares) as a function of the maximum $N_{m}^{2}$ in the $2 \mathrm{D}$ runs with wind stress as -0.04 (blue), -0.04 (red), and $-0.08 \mathrm{~Pa}$ (black).

parameter $N_{m}^{2}$ (Fig. 5c). Figure 14a shows the correlation between the maximum values of $N_{m}^{2}$ and $\Delta \rho_{d} / \Delta x$, within each cycle identified in all $2 \mathrm{D}$ runs. A linear correlation $(r=0.84)$ is found between the two parameters, which that can be expressed as

$$
N_{m}^{2}=-a_{3} \frac{1}{\alpha} \frac{g}{\rho_{0}} \frac{\Delta \rho_{d}}{\Delta x}
$$

with $a_{3}=1.87$. This correlation is not surprising, as the evolution of the density field can be simplified as a slumping of the isopycnals and the bottom slope $\alpha$ controls the ratio of the cross-shore length scale to the vertical scale. Previous studies (Weatherly and Martin 1978; Lentz 1992; Tilburg 2003) have shown that both surface and bottom mixed layer thicknesses depend on shear velocity (surface and bottom, respectively) and stratification. The mixed layer thickness can be approximated as (Weatherly and Martin 1978)

$$
D_{m}=\frac{a_{4} u_{*}}{f\left(1+\frac{N^{2}}{f^{2}}\right)^{1 / 4}},
$$

where $a_{4}$ is a constant. Because of the unsteadiness of each cycle in the 2D runs, it is difficult to directly estimate the value $N^{2}$ corresponding to $D_{1}$ or $D_{2}$. Here we assume that the corresponding $N^{2}$ values are both proportional to the maximum $N_{m}^{2}$ during each cycle, and that Eq. (4.8) can be used to quantify $D_{1}$ and $D_{2}$ by substituting the maximum $N_{m}^{2}$ for $N^{2}$. Figure $14 \mathrm{~b}$ shows the fitting results for all the $2 \mathrm{D}$ run cycles. For $D_{1}, a_{4}=$ 5.2 and the correlation coefficient is 0.93 ; for $D_{2}, a_{4}=2.6$ and the correlation coefficient reaches 0.97 .

Thus, for the 2D runs, the conversion of cross-shore density gradient to vertical stratification can be expressed using Eq. (4.7). Moreover, Eq. (4.6) suggests that the critical cross-shore density gradient $\partial \rho_{d} / \partial x$ value can be quantified as a function of water depth, wind stress, and heat loss rate. By combining Eqs. (4.6)-(4.8), both $D_{1}$ and $D_{2}$ are found to be proportional to the quantity $a_{2}^{-1 / 2} f^{-5 / 4} \sqrt{\alpha}\left|B / B_{0}\right|^{-\gamma / 2} \sqrt{|\tau| / \rho_{0}}$, with $\gamma=0.43$ from Eq. (4.6). This reveals that depths $D_{1}$ and $D_{2}$ increase with increasing shelf slope and/or reduced heat loss rate, as both factors lead to a weaker inner shelf stratification as the isopycnals slump. The different exponents of $\alpha$ and $B$ (i.e., 0.5 and -0.21 , respectively) indicate that the outer boundary of the inner shelf is more sensitive to changes in shelf slope than changes in heat loss rate.

Compared with the cyclic fluctuation of the inner shelf extent in 2D runs, the irregular fluctuation in 3D runs is much smaller. Figure 15 shows the mean and standard deviation of the depth of the inner-shelf outer boundary $D$ during the last 50 days for all $3 \mathrm{D}$ runs. These values are plotted against the quantity $\sqrt{\alpha}|B|^{-\gamma / 2} \sqrt{|\tau| / \rho_{0}}$ and a linear fitting is carried out with a correlation coefficient of 0.98 (Fig. 15d). The linear fitting slightly overestimates (underestimates) the $D$ value for slope $\alpha=1.0 \times 10^{-3}\left(0.5 \times 10^{-3}\right)$. This disagreement is primarily attributed to the inaccuracy of the vertical stratification introduced by Eq. (4.7) (see Fig. 14a). The $N_{m}^{2}$ value for slope $\alpha=1.0 \times 10^{-3}\left(0.5 \times 10^{-3}\right)$ is 

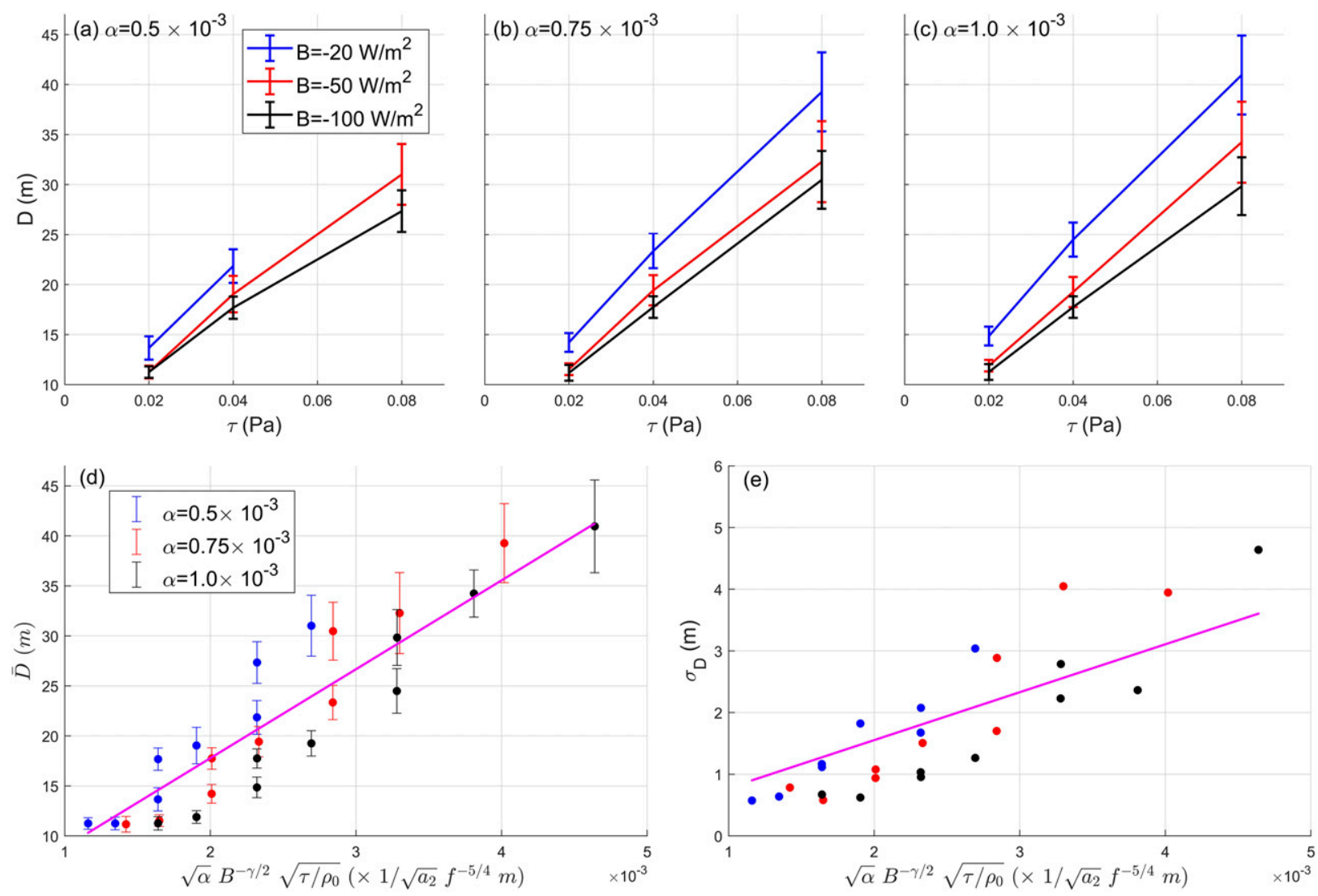

FIG. 15. (top) Mean and standard deviation (error bars) of the depth of the inner shelf outer boundary $D$ as the wind stress changes in the 3D runs with a bottom slope of (a) $\alpha=0.5 \times 10^{-3}$, (b) $\alpha=0.75 \times 10^{-3}$, and (c) $\alpha=1.0 \times 10^{-3}$. (bottom) Fitting of the (d) mean values of $D$ and (e) its standard deviation $\sigma_{D}$ as a function of $\sqrt{\alpha}|B|^{-\gamma / 2} \sqrt{|\tau| / \rho_{0}}$. All values of $D$ are calculated during the last 50 days of the runs.

underestimated (overestimated) by Eq. (4.7). A smaller $N_{m}^{2}$ is predicted for slope $\alpha=1.0 \times 10^{-3}$, which results in a bigger $D$ value in the linear fitting using the proposed quantity. Additionally, the standard deviation of $D$ is also well correlated with the proposed quantity (Fig. 15e). Ideally, the standard deviation of $D$ can reach the range defined by $\left(D_{2}, D_{1}\right)$ in the $2 \mathrm{D}$ runs, if the instabilities become negligible. The correlation between $D$ and the proposed quantity in the 3D runs is not surprising, as the cross-shore heat flux in the 3D runs is still dominated by the winddriven mean component (see section 3d; Fig. 12). The much smaller eddy component leads to a slight enhancement of the total cross-shore heat flux if compared with the 2D results (Fig. 5a). In the 3D runs, the cyclic fluctuation of the inner shelf outer boundary can still be seen (Fig. 4b), even though it is not as extreme as that in the $2 \mathrm{D}$ runs.

\section{c. EKE variability}

In here we follow B17 and attempt to quantify the dependence of EKE on $f, \alpha, B$, and $\tau$. We also use the ratio of the alongshore current acceleration induced by the wind to that by the surface cooling, defined as

$$
\Omega=\frac{C_{p} f \tau}{g \alpha_{T} \alpha B},
$$

to relate EKE under wind forcing to that under no wind forcing $\left(\mathrm{EKE}_{0}\right)$ using the same relationship as in B17:

$$
\mathrm{EKE}=\mathrm{EKE}_{0} \frac{a_{5}}{1+a_{6} \sqrt{|\Omega|}}
$$

A least squares fitting of Eq. (4.10) is carried out using the results from all 3D runs and this is shown in Fig. 16. Under downwelling conditions, the fitting estimated $a_{5}=0.95$ and $a_{6}=0.66$ (with $r=0.98$ ), which is consistent with the results in B17. However, under upwelling conditions, the coefficients estimated $\left(a_{5}=0.99\right.$, $a_{6}=0.18$ with $\left.r=0.94\right)$ are different from those in B17 and our data seem to not be explained well by Eq. (4.10) in this case. Our analysis suggests that as $\Omega$ increases, the shelf tends to become more barotropic and the flow could be more affected by the bottom friction, leading to enhanced dissipation and inhibition of the instability development. This is different from the slight enhancement of 


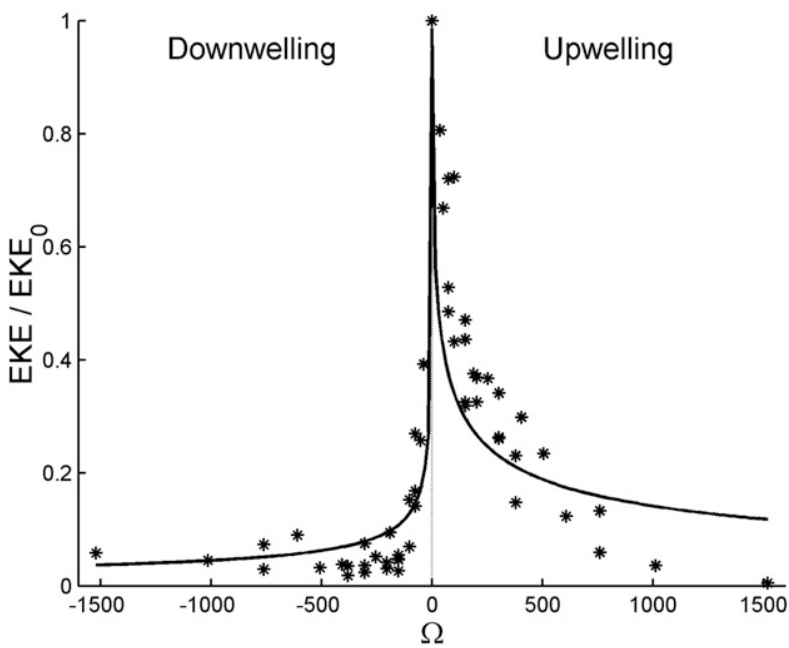

FIG. 16. Correlation between normalized EKE and the quantity $\Omega$ for all the 3D runs. The fitting lines are calculated from Eq. (4.10).

EKE found in B17. In these upwelling condition runs, the root-mean-square error reaches $13 \%$ of $\mathrm{EKE}_{0}$. This deviation may be reduced by incorporating the effects of wind-driven density advection in Eq. (4.10), in addition to the current shear induced by wind stress. Consideration of wind-driven density advection seems to be more challenging, as it is dependent on the variable stratification on the shelf.

\section{d. Practical implications}

In reality, both wind forcing and heat flux are highly variable, and circulation dynamics are more complicated than those revealed by our idealized simulation results. Figure 17 shows a typical observation of the wintertime sea surface temperature (SST), and crossshore profiles of seawater temperature, salinity, and density in the SAB off the coast of South Carolina. The 24-h-averaged surface currents, measured by an $8.3-\mathrm{MHz}$ high-frequency $(\mathrm{HF})$ radar are also presented. In the cross-shore direction, SST gradually increases from $10^{\circ} \mathrm{C}$ close to the coastline to $22^{\circ} \mathrm{C}$ around the $50-\mathrm{m}$ isobath. The SST imagery indicates the development of density fronts that vary spatially in the alongshore. Alongshore variations of the surface flow are also visible, especially near the $25-\mathrm{m}$ isobath, indicative of instabilities. The salinity variability is small (Fig. 17c) and cross-shore density gradient is primarily determined by temperature gradient. The value of $\partial \rho_{d} / \partial x$, averaged over the first $10 \mathrm{~km}$ of the cross-shore coordinate, reaches $2.0 \times 10^{-5} \mathrm{~kg} \mathrm{~m}^{-4}$. If we assume vertical convection to be the main mechanism responsible for the density gradient, then the duration of constant heat loss rate required to build the estimated cross-shore density gradient can be estimated from Eq. (3.2). Using $h=27 \mathrm{~m}$ and $\alpha=0.5 \times 10^{-3}$ at this location, a duration of approximately 80 and 160 days is estimated for $B$ values of -100 and $-50 \mathrm{Wm}^{-2}$, respectively. Thus, our simulated density field reflects conditions that are relevant to winter cooling in the SAB.

The seasonally mean winter winds are from the northnorthwest (Weber and Blanton 1980; Blanton et al. 2003), and the direction fluctuates constantly around this mean during the frequent passages of the winter storms $(\mathrm{Wu}$ et al. 2017). Although the unrealistic wind forcing used in this work does not capture these temporal characteristics, our results demonstrate that, under relatively
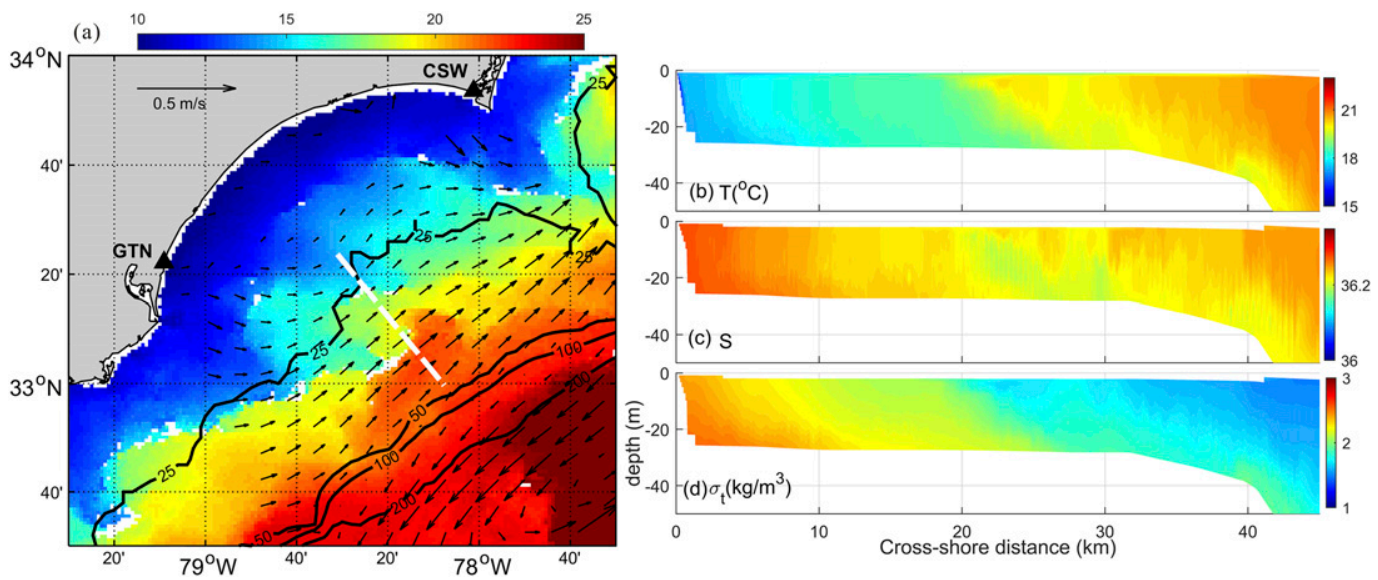

FIG. 17. (a) Daily average of SST (color contours) and surface current vectors off the South Carolina coast on 17 Jan 2014. (right) Cross-shore profiles of (b) SST, (c) salinity $S$, and (d) density anomaly $\sigma_{t}$ along the central transect shown as a dashed white line in (a) on 1 Feb 2012. SST was measured by NOAA's Advanced Very High Resolution Radiometer and the surface currents were measured by high-frequency radars from the University of South Carolina [two triangles in (a) show the station locations]. All data in the right panels are obtained from the Long Bay Wintertime Bloom Project. 
strong downwelling-favorable wind conditions, instabilities are inhibited and a cross-shore density gradient develops over time. Under upwelling conditions, winds can also inhibit instabilities, especially for a relatively strong wind on a gentle shelf (with a slope of $\sim 0.5 \times$ $\left.10^{-3}\right)$. It is predicted that if relatively strong winds persist and surface cooling is sustained, then a cross-shore density gradient will develop and APE can be efficiently stored within the water column under both upwelling and dowelling wind conditions. This prediction is consistent with the observed wintertime density profile (Fig. 17d) at this area that is prone to the passages of winter storms.

\section{Summary and conclusions}

The 2D simulations, under downwelling winds, have revealed that the initial horizontal (cross shore) density gradient is converted into vertical stratification. This occurs through isopycnal slumping once the cross-shore density gradient reaches a critical condition. For 3D runs, instabilities promote stratification that enhances winddriven downwelling. Under upwelling conditions, crossshore exchange is effectively inhibited in 2D runs, when compared with that in the $3 \mathrm{D}$ runs.

Under downwelling conditions in the 2D runs, both the offshore and onshore depth limits of the inner-shelf outer boundary depend on buoyancy flux, wind stress, and shelf slope, and it is proportional to the multiparametric quantity $a_{2}^{-1 / 2} f^{-5 / 4} \sqrt{\alpha}\left|B / B_{0}\right|^{-\gamma / 2} \sqrt{|\tau| / \rho_{0}}$ (with $a_{2}$ as a dimensional constant and $\gamma=0.43$ ). This relationship is valid even for the $3 \mathrm{D}$ runs under downwelling conditions; increased wind stress, or decreased heat loss rate, tend to constrain the instabilities, and a cross-shore exchange pattern similar to that found in the $2 \mathrm{D}$ runs is found. Under upwelling conditions, instabilities weaken as the wind stress increases. This is caused primarily by the enhancement of the turbulence frictional dissipation. Even though instabilities are inhibited, cross-shore eddy heat flux still dominates over the mean heat flux.

There are several questions remaining that require further research. The effects of bottom friction need more consideration. Moreover, this work is limited to idealized numerical simulations. Verification of the results requires careful observations over a variety of forcing conditions.

Acknowledgments. The work presented here was partially supported by the Southeast Coastal Ocean Observing Regional Association (SECOORA) pursuant to National Oceanic and Atmospheric Administration Award NA16NOS0120028. The two anonymous reviewers are thanked for their valuable comments. The manuscript was finalized while G. Voulgaris was serving at the National Science Foundation. Any opinions, findings, and conclusions or recommendations expressed in here are those of the authors and do not necessarily reflect the views of any of the funding organizations.

\section{REFERENCES}

Atkinson, L. P., J. O. Blanton, W. S. Chandler, and T. N. Lee, 1983: Climatology of the southeastern United States continental shelf waters. J. Geophys. Res., 88, 4705-4718, https://doi.org/ 10.1029/JC088iC08p04705.

Austin, J. A., and S. J. Lentz, 2002: The inner shelf response to wind-driven upwelling and downwelling. J. Phys. Oceanogr., 32, 2171-2193, https://doi.org/10.1175/1520-0485(2002)032<2171: TISRTW $>2.0 . \mathrm{CO} ; 2$.

Blanton, B. O., A. Aretxabaleta, F. E. Werner, and H. E. Seim, 2003: Monthly climatology of the continental shelf waters of the South Atlantic Bight. J. Geophys. Res., 108, 3264, https:// doi.org/10.1029/2002JC001609.

Blumsack, S. L., and P. J. Gierasch, 1972: Mars: The effects of topography on baroclinic instability. J. Atmos. Sci., 29, 1081-1089, https:// doi.org/10.1175/1520-0469(1972)029<1081:MTEOTO>2.0.CO;2.

Bretherton, F. P., 1966: Critical layer instability in baroclinic flows. Quart. J. Roy. Meteor. Soc., 92, 325-334, https://doi.org/10.1002/ qj. 49709239302.

Brink, K. H., 2016a: Cross-shelf exchange. Annu. Rev. Mar. Sci., 8, 59-78, https://doi.org/10.1146/annurev-marine-010814-015717.

_ 2016b: Continental shelf baroclinic instability. Part I: Relaxation from upwelling or downwelling. J. Phys. Oceanogr., 46, 551-568, https://doi.org/10.1175/JPO-D-15-0047.1.

_ 2017: Surface cooling, winds, and eddies over the continental shelf. J. Phys. Oceanogr., 47, 879-894, https://doi.org/10.1175/ JPO-D-16-0196.1.

— , and H. Seo, 2016: Continental shelf baroclinic instability. Part II: Oscillating wind forcing. J. Phys. Oceanogr., 46, 569-582, https://doi.org/10.1175/JPO-D-15-0048.1.

Brown, W. S., and R. C. Beardsley, 1978: Winter circulation in the western Gulf of Maine: Part 1. Cooling and water mass formation. J. Phys. Oceanogr., 8, 265-277, https://doi.org/10.1175/ 1520-0485(1978)008<0265:WCITWG > 2.0.CO;2.

Chapman, D. C., and G. Gawarkiewicz, 1997: Shallow convection and buoyancy equilibration in an idealized coastal polynya. J. Phys. Oceanogr., 27, 555-566, https://doi.org/10.1175/15200485(1997)027<0555:SCABEI >2.0.CO;2.

Garvine, R. W., 2004: The vertical structure and subtidal dynamics of the inner shelf off New Jersey. J. Mar. Res., 62, 337-371, https://doi.org/10.1357/0022240041446182.

Gawarkiewicz, G., and D. C. Chapman, 1995: A numerical study of dense water formation and transport on a shallow, sloping continental shelf. J. Geophys. Res., 100, 4489-4507, https://doi.org/ 10.1029/94JC01742.

Gill, A. E., 1973: Circulation and bottom water production in the Weddell Sea. Deep-Sea Res. Oceanogr. Abstr., 20, 111-140, https://doi.org/10.1016/0011-7471(73)90048-X.

Hart, J. E., 1979: Finite amplitude baroclinic instability. Annu. Rev. Fluid Mech., 11, 147-172, https://doi.org/10.1146/annurev. fl.11.010179.001051.

Horwitz, R., and S. J. Lentz, 2014: Inner-shelf response to cross-shelf wind stress: The importance of the cross-shelf density gradient in an idealized numerical model and field observations. J. Phys. Oceanogr., 44, 86-103, https://doi.org/10.1175/JPO-D-13-075.1. 
$\longrightarrow$, and - 2016: The effect of wind direction on cross-shelf transport on an initially stratified inner shelf. J. Mar. Res., 74, 201-227, https://doi.org/10.1357/002224016820870648.

Ivanov, V. V., G. I. Shapiro, J. M. Huthnance, D. L. Aleynik, and P. N. Golovin, 2004: Cascades of dense water around the world ocean. Prog. Oceanogr., 60, 47-98, https://doi.org/10.1016/ j.pocean.2003.12.002.

Jiang, L., and R. W. Garwood Jr., 1996: Three-dimensional simulations of overflows on continental slopes. J. Phys. Oceanogr., 26, 1214-1233, https://doi.org/10.1175/1520-0485(1996)026<1214: TDSOOO $>2.0 . \mathrm{CO} ; 2$.

Lentz, S. J., 1992: The surface boundary layer in coastal upwelling regions. J. Phys. Oceanogr., 22, 1517-1539, https://doi.org/ 10.1175/1520-0485(1992)022<1517:TSBLIC $>2.0$. CO; 2 .

- 1995: Sensitivity of the inner-shelf circulation to the form of the eddy viscosity profile. J. Phys. Oceanogr., 25, 19-28, https:// doi.org/10.1175/1520-0485(1995)025<0019:SOTISC >2.0.CO;2.

- 2008: Observations and a model of the mean circulation over the Middle Atlantic Bight continental shelf. J. Phys. Oceanogr., 38, 1203-1221, https://doi.org/10.1175/2007JPO3768.1.

- and M. R. Fewings, 2012: The wind- and wave-driven innershelf circulation. Annu. Rev. Mar. Sci., 4, 317-343, https://doi.org/ 10.1146/annurev-marine-120709-142745.

Lin, S. J., and R. T. Pierrehumbert, 1988: Does Ekman friction suppress baroclinic instability? J. Atmos. Sci., 45, 2920-2933, https://doi.org/10.1175/1520-0469(1988)045<2920:DEFSBI > 2.0.CO;2.

Madsen, O. S., 1977: A realistic model of the wind-induced Ekman boundary layer. J. Phys. Oceanogr., 7, 248-255, https://doi.org/10.1175/1520-0485(1977)007<0248:ARMOTW> 2.0.CO;2.

Mahadevan, A., A. Tandon, and R. Ferrari, 2010: Rapid changes in mixed layer stratification driven by submesoscale instabilities and winds. J. Geophys. Res., 115, C03017, https://doi.org/10.1029/ 2008JC005203.

Mathews, T. D. and O. Pashuk, 1984: Shelfwater response to the cold winters of 1977 and 1978 in the South Atlantic Bight (SAB). Litoralia, 1, 41-58.

Mellor, G. L., and T. Yamada, 1982: Development of a turbulence closure model for geophysical fluid problems. Rev. Geophys., 20, 851-875, https://doi.org/10.1029/RG020i004p00851.

Price, J. F., and Coauthors, 1993: Mediterranean outflow mixing and dynamics. Science, 259, 1277-1282, https://doi.org/10.1126/ science.259.5099.1277.

Pattiaratchi, C., B. Hollings, M. Woo, and T. Welhena, 2011: Dense shelf water formation along the south-west Australian inner shelf. Geophys. Res. Lett., 38, L10609, https://doi.org/10.1029/ 2011 GL046816.

Pierrehumbert, R. T., and K. L. Swanson, 1995: Baroclinic instability. Annu. Rev. Fluid Mech., 27, 419-467, https://doi.org/ 10.1146/annurev.fl.27.010195.002223.

Pringle, J. M., 1998: Cooling and internal waves on the continental shelf. Ph.D. thesis, Massachusetts Institute of
Technology, 225 pp., http://dspace.mit.edu/handle/1721.1/ 58861.

- 2001: Cross-shelf eddy heat transport in a wind-free coastal ocean undergoing winter time cooling. J. Geophys. Res., 106, 2589-2604, https://doi.org/10.1029/2000JC900148.

Rogers-Cotrone, J., A. E. Yankovsky, and T. J. Weingartner, 2008: The impact of spatial wind variations on freshwater transport by the Alaska Coastal Current. J. Mar. Res., 66, 899-925, https://doi.org/10.1357/002224008788064603.

Shapiro, G. I., J. M. Huthnance, and V. V. Ivanov, 2003: Dense water cascading off the continental shelf. J. Geophys. Res., 108, 3390, https://doi.org/10.1029/2002JC001610.

Shchepetkin, A. F., and J. C. McWilliams, 2005: The regional oceanic modeling system (ROMS): A split-explicit, freesurface, topography-following-coordinate oceanic model. Ocean Modell., 9, 347-404, https://doi.org/10.1016/j.ocemod.2004.08.002.

Tanaka, K., 2006: Effects of the Earth's rotation and bottom slope on a density current descending a sloping bottom. J. Geophys. Res., 111, C11018, https://doi.org/10.1029/2006JC003677.

Taylor, J. R., and R. Ferrari, 2010: Buoyancy and wind-driven convection at mixed layer density fronts. J. Phys. Oceanogr., 40, 1222-1242, https://doi.org/10.1175/2010JPO4365.1.

Thomas, L., and R. Ferrari, 2008: Friction, frontogenesis, and the stratification of the surface mixed layer.J. Phys. Oceanogr., 38, 2501-2518, https://doi.org/10.1175/2008JPO3797.1.

—_ and J. R. Taylor, 2010: Reduction of the usable wind-work on the general circulation by forced symmetric instability. Geophys. Res. Lett., 37, L18606, https://doi.org/10.1029/ 2010GL044680.

Tilburg, C. E., 2003: Across-shelf transport on a continental shelf: Do across-shelf winds matter? J. Phys. Oceanogr., 33, 2675-2688, https://doi.org/10.1175/1520-0485(2003)033<2675:ATOACS> 2.0.CO;2.

Weatherly, G. L., and P. J. Martin, 1978: On the structure and dynamics of the oceanic bottom boundary layer. J. Phys. Oceanogr., 8, 557-570, https://doi.org/10.1175/1520-0485(1978) $008<0557$ :OTSADO $>2.0 . \mathrm{CO} ; 2$.

Weber, A. H., and J. O. Blanton, 1980: Monthly mean wind fields for the South Atlantic Bight. J. Phys. Oceanogr., 10, 1256-1263, https://doi.org/10.1175/1520-0485(1980)010<1256:MMWFFT> 2.0.CO;2.

Winters, K. B., P. N. Lombard, J. J. Riley, and E. A. D'Asaro, 1995: Available potential energy and mixing in density-stratified fluids. J. Fluid Mech., 289, 115-128, https://doi.org/10.1017/ S002211209500125X.

Wu, X., G. Voulgaris, and N. Kumar, 2017: Parameterization of synoptic weather systems in the South Atlantic Bight for modeling applications. Ocean Dyn., 67, 1231-1249, https://doi.org/ 10.1007/s10236-017-1084-x.

Yoder, J. A., and T. Ishimaru, 1989: Phytoplankton advection off the southeastern United States continental shelf. Cont. Shelf Res., 9, 547-553, https://doi.org/10.1016/0278-4343(89) 90020-4. 